\title{
A numerical study of capacity and stiffness of circular skirted foundations in clay subjected to combined static and cyclic general loading
}

\author{
K. S. SKAU ${ }^{*} \dagger$, Y. CHEN $\$$ and H. P. JOSTAD ${ }^{*} \S$
}

\begin{abstract}
Skirted foundations have been widely applied as offshore foundations for several decades. In design, the use of failure envelopes is convenient for assessing stability under combined loading. A large number of studies on failure envelopes exist in the literature based on experiments and numerical analyses. Most of these studies focus on ultimate capacity and static loading. This paper presents a numerical study focusing on cyclic degradation and failure envelopes for skirted foundations subjected to combined cyclic and static loading. It was found that the shapes of the failure envelopes are little affected by degradation expressed by the number of equivalent cycles. In addition to failure envelopes, contours of displacements were computed in the three-dimensional load space (vertical, horizontal and moment load) for a more complete description of the response. As an example, the well-defined cyclic contour diagrams of Drammen clay were utilised to demonstrate how foundation response diagrams can be established. The database is accompanied by a simplified procedure to account for cyclic degradation through equivalent number of cycles, different normalised load-displacement response and variation in foundation geometry. The framework of procedures can be used to estimate foundation stiffness and capacity and the results can serve as a basis for the development of foundation macro-element models.
\end{abstract}

KEYWORDS: footings/foundations; offshore engineering

\section{INTRODUCTION}

Circular skirted foundations are, as the name indicates, shallow circular foundations equipped with skirts embedded into the seabed. The embedded skirts provide additional stiffness and capacity to the foundation, but give only a modest increase in the foundation weight. The advantages of skirted foundations compared to foundations resting on the seabed are well documented in several studies (Andersen \& Jostad, 1999; Villalobos et al., 2003; Cassidy et al., 2004; El Sawwaf \& Nazer, 2005; Jostad \& Andersen, 2006; Singh et al., 2007). The concept has been used in offshore foundation engineering in various soil conditions for more than 40 years. Skirted gravity-based structures (GBS), suction anchors for floating platforms, spudcans equipped with skirts, suction caissons on jackets and mono-caissons for offshore wind turbines are all examples of shallow foundations with skirts.

It is necessary to consider the cyclic nature of the environmental loads as well as the combination of vertical $(V)$, horizontal $(H)$ and moment $(M)$ loads in the design of foundations to be installed offshore. The combination of loads applied to a skirted foundation strongly depends on the structural configuration. A single skirted foundation

Manuscript received 8 April 2016; revised manuscript accepted 9 June 2017. Published online ahead of print 19 July 2017.

Discussion on this paper closes on 1 August 2018, for further details see p. ii.

Published with permission by the ICE under the CC-BY license. (http://creativecommons.org/licenses/by/4.0/)

* NGI (Norwegian Geotechnical Institute), Oslo, Norway.

$\dagger$ Faculty of Engineering and Technology, NTNU, (Norwegian

University of Science and Technology), Trondheim, Norway (Orcid:0000-0002-3059-2081).

† ÅF Reinertsen, Oslo, Norway.

$\S$ Faculty of Engineering and Technology, NTNU, (Norwegian

University of Science and Technology), Trondheim, Norway. supporting an offshore wind monopod structure will be subjected to large overturning moments, whereas for skirted foundations (e.g. suction buckets) supporting a jacket structure, the large overturning moment is transferred into vertical load pairs applied onto each of the foundations. However, the present study is not limited to a specific application or structural configuration and all load combinations are therefore considered equally relevant.

Most results presented herein will be described in the framework of failure envelopes, which has roots back to the work by Roscoe \& Schofield (1957). The advantages of failure envelopes are thoroughly discussed in the literature (Gottardi \& Butterfield, 1993; Houlsby \& Cassidy, 2002; Gourvenec \& Randolph, 2003; Gourvenec \& Barnett, 2011). The failure envelope approach is generally less conservative than classical bearing capacity equations, such as Meyerhof (1951), Meyerhof (1953), Brinch Hansen (1961) and Brinch Hansen (1970). They provide a direct illustration of the effect of combined loading and the mobilisation level, and particularly how changes in individual load components affect the global mobilisation. The properties of failure envelopes for skirted foundations have been investigated extensively in a number of experimental and numerical studies. The studies have considered how the shape and size of the failure envelopes are affected by the embedment depth, foundation geometry, shear strength profile, undrained and drained conditions, deformable and non-deformable soil plug and limited interface shear and tension strength (Jostad et al., 1994; Martin, 1994; Ukritchon et al., 1998; Taiebat \& Carter, 2000; Villalobos, 2006; Gourvenec, 2008; Bransby \& Yun, 2009; Randolph \& Gourvenec, 2011; Vulpe et al., 2014; Gerolymos et al., 2015; Ntritsos et al., 2015; Vulpe, 2015). The present numerical study considers the undrained response of circular skirted foundations in clay subjected to combined static and cyclic general loading. The results from the study include trends in both size and shape of failure envelopes when subjected to cyclic loading, and in 


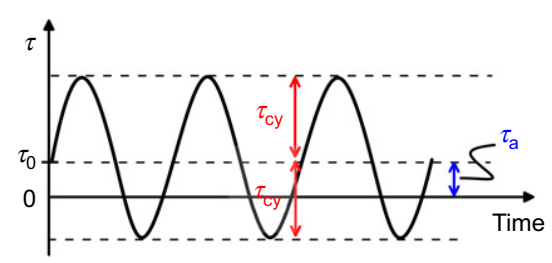

(a)

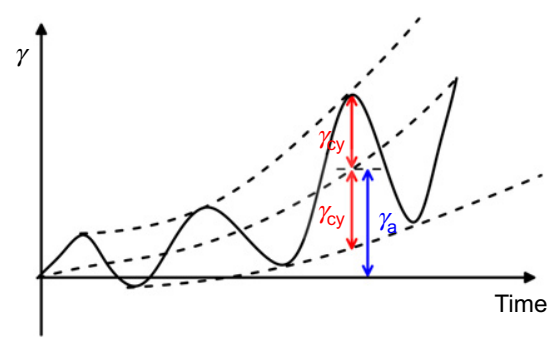

(b)

Fig. 1. Definition of cyclic and average (a) shear stress and (b) shear strain (after Andersen, 2015)

addition contours of displacements from combined loading in the $V-H-M$ load space. The effect of cyclic loading is based on the cyclic behaviour of soil elements as described in Andersen (2015). The results from this study have two major applications: $(a)$ the suggested procedure and the results can be used to estimate the effect of cyclic loading on stiffness and capacity of skirted foundations in clay; $(b)$ the results can be used as a basis for the development of foundation models (macro elements) as they reveal fundamental trends of the behaviour of skirted foundations subjected to cyclic loading in the three-dimensional (3D) load space.

\section{CLAY SUBJECTED TO CYCLIC LOADING}

Cyclic loading significantly affects the behaviour of soil and foundations and has been the subject of intense research since the early studies in the late 1960s by, for example, Seed \& Lee (1966), Seed (1968), Ishihara et al. (1975) and Andersen (1976). The importance to foundation engineering problems is also well documented (e.g. Clausen et al., 1975; Randolph \& Gourvenec, 2011; Andersen et al., 2013; Andersen, 2015). When clay is subjected to cyclic loading, it may undergo significant de-structuration and accumulation of pore pressure. The undrained shear strength and stiffness of the clay are then gradually reduced; this process is often denoted as cyclic degradation.

\section{The NGI procedure accounting for cyclic loading}

The Norwegian Geotechnical Institute (NGI) procedure is based on cyclic laboratory element testing along relevant stress paths. The applied stress and resulting strain and pore pressure are divided into cyclic and average parts, as illustrated in Fig. 1. After several tests with different shear stress levels and cyclic-to-average shear stress ratios, the results are interpreted and presented in contour diagrams as described in Andersen (2015). The diagrams will then contain information about the relationship between cyclic shear stress $\left(\tau_{\mathrm{cy}}\right)$, average shear stress $\left(\tau_{\mathrm{a}}\right)$, cyclic shear strain $\left(\gamma_{\text {cy }}\right)$, average shear strain $\left(\gamma_{\mathrm{a}}\right)$, cyclic pore pressure $\left(u_{\mathrm{cy}}\right)$, average pore pressure $\left(u_{\mathrm{a}}\right)$ and number of cycles $(N)$. The diagrams are based on triaxial compression tests, triaxial extension tests and direct simple shear (DSS) tests (Bjerrum \& Landva, 1966). Fig. 2 shows an example of a full 3D DSS contour diagram where the cyclic and average shear strain $\left(\gamma_{c y}\right.$ and $\left.\gamma_{\mathrm{a}}\right)$ are given as functions of cyclic and average shear stress $\left(\tau_{\text {cy }}\right.$ and $\left.\tau_{\mathrm{a}}\right)$ and number of cycles $N$.

An extensive database of cyclic laboratory tests exists at NGI from more than 40 years of offshore geotechnical engineering and research. Particularly well defined is the cyclic behaviour of Drammen clay, where data exist for different overconsolidation ratios (OCRs). The variation in OCR is made possible by pre-consolidation of the clay in the test apparatus to different stress levels. This makes the database representative for a wider range of clays. For

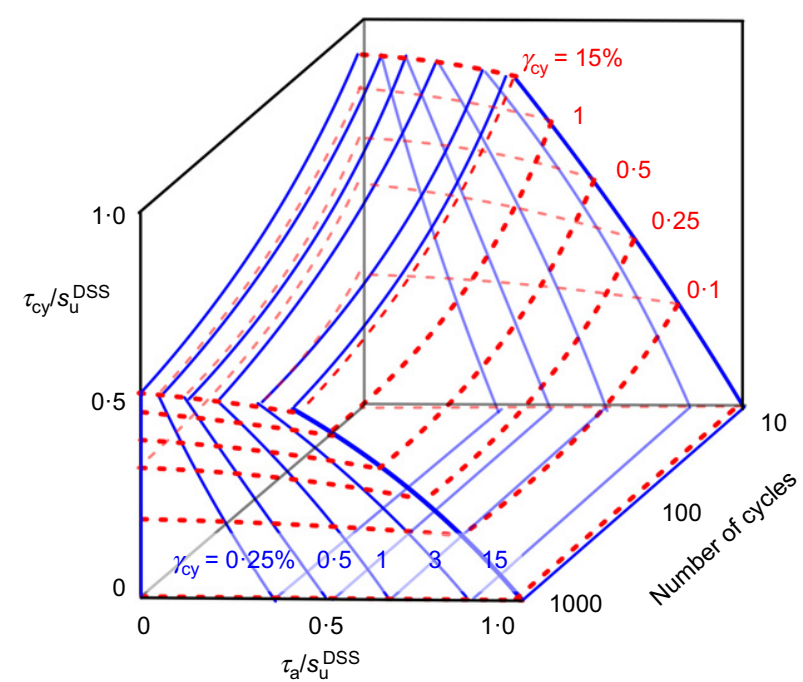

Fig. 2. DSS contour diagram with cyclic $\left(\gamma_{c y}\right)$ and average shear strain $\left(\gamma_{\mathrm{a}}\right)$ in a 3D space of cyclic shear stress $\left(\tau_{\mathrm{cy}}\right)$, average shear stress $\left(\tau_{\mathrm{a}}\right)$ and number of cycles $N$ (after Andersen, 2015)

approximations, the results presented herein may therefore be applicable to clays other than Drammen clay. However, if the results are used in design, the cyclic behaviour of the clay has to be compared with the cyclic properties of Drammen clay, for example by comparing the degradation of the shear strength as a function of the number of cycles. The cyclic data of Drammen clay are presented in several publications (Andersen, 1976, 2004, 2015; Andersen et al., 1980).

Using the contour diagrams, it is possible to account for the effect of a cyclic shear stress history. An irregular shear stress history in time is re-organised into a history of 'shear stress groups', where cycles of similar magnitude and average shear stress are placed in the same group, as described by Norén-Cosgriff et al. (2015). The re-organised 'group history' can then be applied to or followed in contour diagrams according to the accumulation procedure (Andersen, 2015), and the number of equivalent cycles, $N_{\text {eq }}$, can be determined. The physical meaning of $N_{\text {eq }}$, is that a full irregular shear stress history can be represented by a number of equivalent cycles $\left(N_{\text {eq }}\right)$ of a given cyclic and average shear stress. In boundary value problems, finite-element analysis (FEA) can be used to determine the $N_{\text {eq }}$ in all integration points in the soil by the undrained cyclic accumulation model (UDCAM) (Jostad et al., 2014). The spatial variation of $N_{\text {eq }}$ can be substantial in problems that experience a large degree of stress redistribution - for example, flexible piles in layered soils (Jostad et al., 2014). However, skirted shallow foundations will normally be relatively stiff compared to the soil and have a well-defined critical slip surface. In these problems, $N_{\text {eq }}$ is often assumed to be homogeneous in the near-field foundation soil. The assumption has been used and validated for GBS design (Andersen et al., 1989, 1993). 
The assumption makes it possible to define stress-strain curves for a 'global' $N_{\text {eq }}$ and compute the foundation response representing the same $N_{\text {eq }}$.

\section{FINITE-ELEMENT MODELS AND ANALYSES}

The analyses are carried out by the in-house program HVMcap (Jostad \& Andersen, 2015) and the commercially available software Plaxis 3D AE (Plaxis, 2015). HVMcap is a quasi-3D program which combines two-dimensional (2D) FEA with '3D side shear contributions'. In the study presented herein, HVMcap has been used for capacity analyses and computation of failure envelopes. Plaxis 3D $\mathrm{AE}$ has a complete $3 \mathrm{D}$ formulation and has been used to compute stiffness response. The main reason for using HVMCap for capacity calculations was to benefit from the computational speed and cover a larger variety of conditions. In both programs, the NGI-ADP model (Grimstad et al., 2012) has been used for modelling the soil. The NGI-ADP model assumes undrained incompressible soil and has an anisotropic shear strength failure criterion. The non-linear shear stress-shear strain response starts with $G_{\max }$ and depends further on the applied stress path according to the anisotropic formulation. The stress-strain curves do not represent single cycles of loading and unloading, but give the final response (combined average and cyclic strain at peak shear stress) which has evolved after $N$ cycles of a given shear stress amplitude combined with a constant average shear stress. This approach, which considers the evolving strains from one or several cycles rather than the actual stress-strain loop within a single cycle, is consistent with the NGI procedure for cyclic loading of soils and is well known from fatigue analyses of metals; it is sometimes referred to as explicit cyclic modelling (Wichtmann et al., 2009). The foundation itself and the soil plug between the skirts were modelled as non-deformable. This simplification excludes any failure mode involving the soil in-between the skirts. However, the simplification is intended as internal stiffeners are often included in design of skirted foundations to ensure structural integrity and to avoid these types of geotechnical failure modes. Reference is made to Vulpe (2015) for the effect of the deformable soil plug. The foundation diameter $D$ is kept constant at $10 \mathrm{~m}$ throughout the paper.

\section{Three-dimensional FE model and analyses}

In the 3D FEA, the foundation was modelled as a circular and perfectly rigid body. To reduce the computational time, symmetry along the foundation centre was utilised and only half of the foundation was modelled. The side boundaries were located $90 \mathrm{~m}$ from the foundation centre, and the bottom boundary $60 \mathrm{~m}$ below the seabed. The influence of the boundaries was checked and found to be negligible for the displacement magnitudes considered in this study. Interface elements were extended outside the foundation corners to reduce the discretisation error. The standard ten-noded tetrahedral element was used to model the soil. The typical element size around the singular points of the foundation was $<0.5 \mathrm{~m}$. The vertical bearing capacity computed by the $3 \mathrm{D}$ FEA was compared with a $2 \mathrm{D}$ axisymmetric analysis on a model with very fine mesh in Plaxis 2D (Plaxis, 2015). The comparison indicated an overshoot of $<3 \%$ in the 3D FEA. This is considered to be sufficiently accurate. The soil-structure interfaces allow for full tension and an interface shear strength reduction factor $\alpha=0.65$ was used in all analyses. Reference is made to Andersen \& Jostad (2002) and Chen \& Randolph (2007) for details on the topic of interface strength. Fig. 3 shows a 3D FE-model with a foundation with diameter, $D=10$, and a skirt depth, $h=10 \mathrm{~m}$.

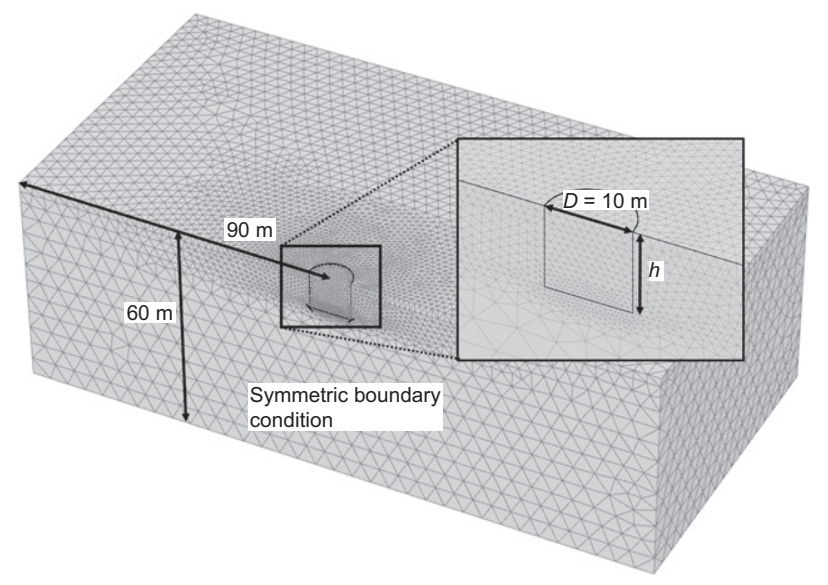

Fig. 3. Three-dimensional FE model with a foundation with aspect ratio $h / D=1$

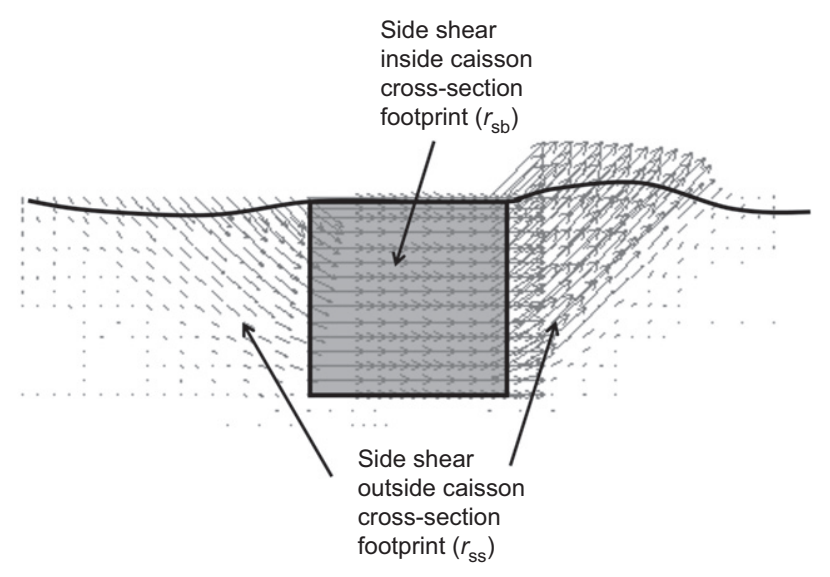

Fig. 4. Illustration of the principle of integrated in-plane side shear resistance, and the separation of side shear factors $r_{\mathrm{sb}}$ and $\boldsymbol{r}_{\mathrm{ss}}$

\section{HVMcap model and analyses}

In the HVMcap FEA, the foundation was modelled as a square foundation with an area equivalent to the circular foundation area. The program runs a plane strain 2D FEA with contact surfaces at the two 'in-plane surfaces' of the model. The side shear is then gradually mobilised as a function of the displacements based on a non-linear hardening function times the direct simple shear strength multiplied by a side shear factor. The side shear factors have been calibrated to fit a realistic $3 \mathrm{D}$ resistance for a circular foundation. The program distinguishes between the side shear factor $\left(r_{\mathrm{sb}}\right)$ for the in-plane cross-sectional area of the caisson, and the factor $\left(r_{\mathrm{ss}}\right)$ for the in-plane crosssectional area of the soil, which extends the in-plane caisson cross-section. The principle is illustrated in Fig. 4. The factors used in the current project are $r_{\mathrm{sb}}=0.5$ and $r_{\mathrm{ss}}=0.6$, similar to the values used in the back calculation presented in Andersen et al. (2005). The study by Jostad \& Andersen (2015) suggests that the factors may be slightly higher for the considered foundation geometries. It should be highlighted that the factors do not refer to the interface strength, but represent a simplified method of accounting for the 3D effects for the actual failure mode. Separate reduction factors exist for the soil-structure interfaces. Similar to the 3D FEA, the soil-structure interfaces allow for full tension and an interface reduction factor $\alpha=0.65$ was used in all analyses for convenience. 


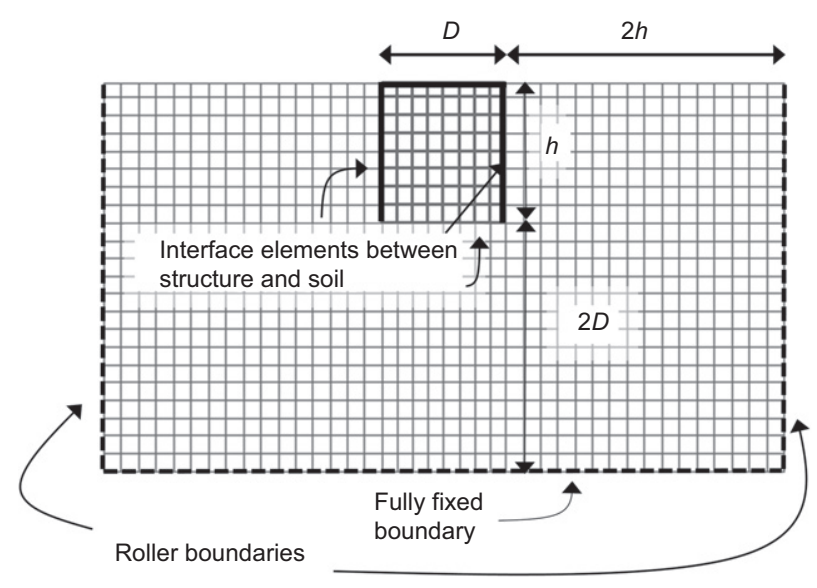

Fig. 5. HVMCap FE model with a foundation with aspect ratio $h I D=1$

The external side boundaries are fixed in the horizontal direction and the bottom boundary is fixed in both horizontal and vertical directions. The side boundaries are located at a distance $2 h$ from the foundation periphery where $h$ is the skirt depth, and the bottom boundary is located $2 D$ below the skirt tip where $D$ is the foundation diameter. Fig. 5 shows the FE model of a foundation with diameter, $D=10 \mathrm{~m}$, and skirt depth, $h=10 \mathrm{~m}$.

\section{Verification of FEA}

The quasi 3D analyses are approximations to full 3D FEA, and the results are therefore not given in absolute numbers, but in a normalised form. This means that the results can be used by denormalising the results. The accuracy of the FEA was therefore assessed by comparing computed normalised failure envelopes. The comparison considered envelopes in all three load planes ( $H V, H M$ and $M V)$. The out-of-plane load is zero in the $H V$ and $M V$ load planes. The computed normalised failure envelope in the $H M$ plane was compared with results available in the literature. The analyses were carried out with rough soil-skirt contact and $h / D=0.5$ for a profile with constant undrained shear strength. The loaddisplacement reference point was taken at the skirt tip in this particular analysis in order to be able to compare the results with those in the literature. Fig. 6(a) shows the normalised failure envelopes in the $H M$ load plane at $V / V_{\max }=0.5$ computed by HVMCap (this study) and the envelopes from former studies (Gourvenec, 2008; Vulpe et al., 2014; Ntritsos et al., 2015). The strip and square representations in the referred studies had an aspect ratio of $h / B=0 \cdot 5$, where $B$ is the width of the foundation. In the $M V$ and $H V$ load plane, 3D FEA results were compared with HVMCap results. The comparison of the failure envelopes in the $H V$ load plane and $M V$ load plane are shown in Figs 6(b) and 6(c). The agreement in Fig. 6 is satisfactory for all considered load planes.

\section{Soil profiles considered}

Two profiles, one with constant shear strength and one with shear strength increasing linearly with depth, were considered in this study. The profiles with increasing shear strength had a constant strength, $s_{\mathrm{u} 0}$, the first metre below the seabed. The shear strength profiles are illustrated in Fig. 7.

Other comparable studies have typically described the foundation response at a reference point located at the seabed or at the skirt tip depth. However, the present study uses an approximate location of the decoupling point as the load reference point. This has the advantages of linking displacements to the applied loads in an intuitive manner and locating the maximum loads along the three main axes. The location is only an approximation since the exact location of the decoupling point depends on load combination, load level, depth to diameter aspect ratio and shear strength gradient. The point is located $2 h / 3$ below the seabed for increasing shear strength profiles and $h / 2$ below the seabed for constant shear strength profiles, where $h$ is the skirt depth. A horizontal load applied to these points gives pure horizontal sliding. The locations of the load reference points are required for the procedure explained later in the paper, which accounts for the effect of different foundation geometry on the response.

\section{Soil properties}

Drammen clay is a natural, normally consolidated, soft clay with typical characteristic of plasticity index $I_{\mathrm{p}}=27 \%$, water content $w=52 \%$ and a clay fraction of $45-55 \%$. To extend the database and reflect overconsolidated clays, samples have been consolidated in the triaxial cell to higher vertical stress $\left(\sigma_{\mathrm{pc}}^{\prime}\right)$ and unloaded to $\sigma_{\mathrm{v}}^{\prime}$. The OCR is then determined as OCR $=\sigma_{\mathrm{pc}}^{\prime} / \sigma_{\mathrm{v}}^{\prime}$. Complete cyclic contour diagrams of Drammen clay with $\mathrm{OCR}=1,4$ and 40 are generated in this way and used in the present study. Reference is made to Bjerrum (1967) and Andersen et al. (1980) for more information about Drammen clay and the cyclic testing. In this study, OCR $=1$ and 4 were used to represent the linearly increasing shear strength and OCR $=40$ was used to represent the profile with constant shear strength. Table 1 gives the undrained static DSS strength for the clays used in the analyses assuming the effective vertical stress $\sigma_{\mathrm{v}}^{\prime}$ based on the submerged soil weight of $\gamma^{\prime}=10 \mathrm{kN} / \mathrm{m}^{3}$. The foundation capacity based on these shear strength profiles serves as the static reference capacity or average reference capacity, $F_{\text {a,ref, which is used for }}$ normalisation of the cyclic capacity presented later.

As stresses are unevenly distributed in the soil around the foundation, the ratio between cyclic and average shear stress in a soil element may deviate from the ratio between the cyclic and average load applied to the foundation. However, the stresses have to be in equilibrium with the global load, and the evolving strains have to be compatible along the failure surface at global failure. In this study, the shear stressstrain curves were defined prior to the analyses. The stress paths in the contour diagrams were therefore based on two simple principles: $(a)$ the ratio between average and cyclic foundation loads are equal to the ratio between average and cyclic shear stresses in the DSS element; $(b)$ the compression and extension stress paths in the triaxial contour diagram are dictated by the evolving strains in the DSS element. These assumptions have been checked and found acceptable throughout the analyses by the advanced soil model UDCAM (Jostad et al., 2014). The simplification provides a relation between $\tau_{\mathrm{cy}} / \tau_{\mathrm{a}}$ on the soil element level and $F_{\mathrm{cy}} / F_{\mathrm{a}}$ on the foundation level. Results will hereafter be denoted with cyclic and average foundation loads rather than stresses. Fig. 8 shows an example of data points from contour diagrams and corresponding curve fit with the soil model representing the case $N_{\text {eq }}=1, F_{\mathrm{y}} / F_{\mathrm{a}}=1$ and $\mathrm{OCR}=1$.

\section{EFFECT OF CYCLIC CAPACITY ON UNIAXIAL LOADING}

The effect of cyclic loading was first studied by considering uniaxial loading along the load axes $V, H$ and $M$. The capacities were computed for different numbers of equivalent cycles, $N_{\text {eq }}$, and different cyclic-to-average load ratios. The 


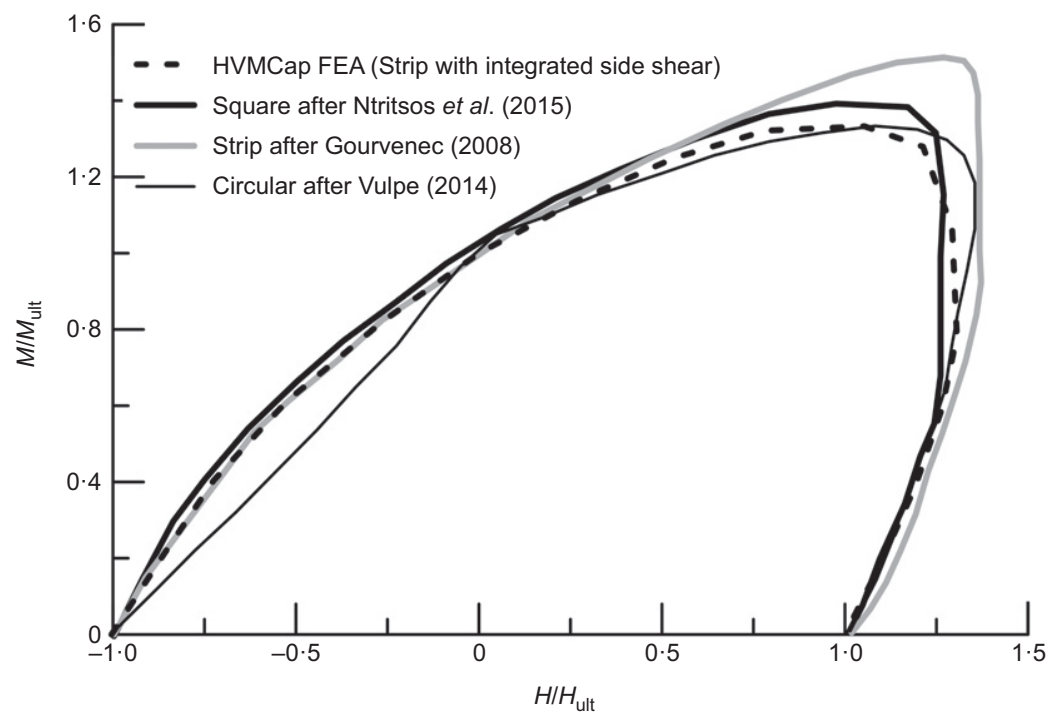

(a)

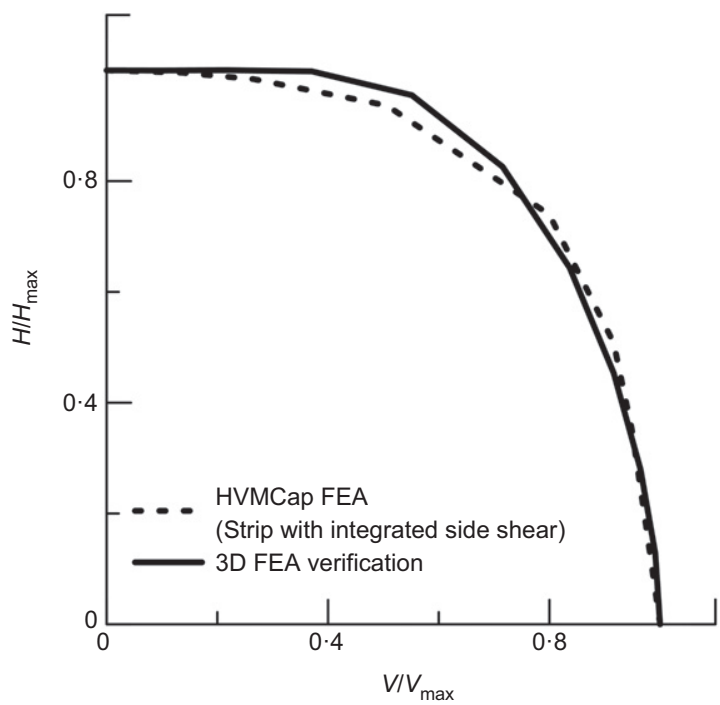

(b)

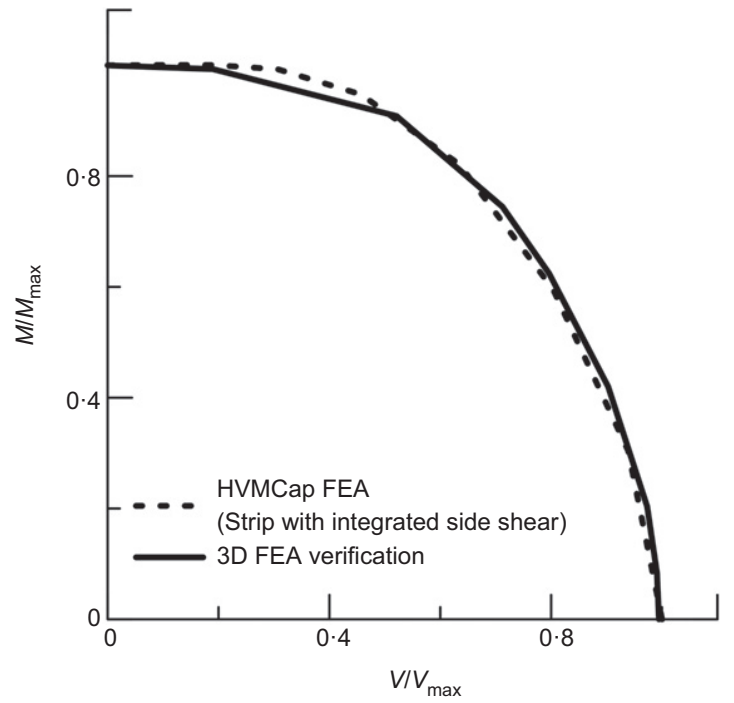

(c)

Fig. 6. Verification of normalised failure envelope from HVMCap FEA in the present study against (a) previous numerical studies in the $H M$ load plane; (b) 3D FEA in the $H V$ load plane; and (c) 3D FEA in the $M V$ load plane

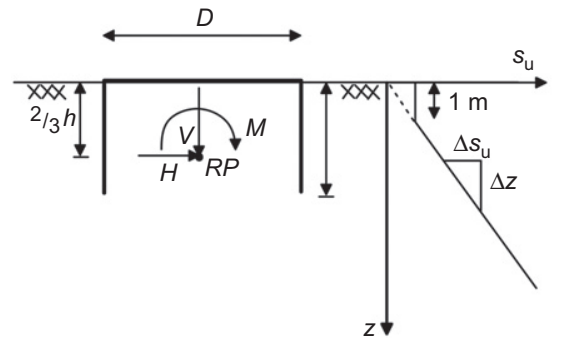

(a)

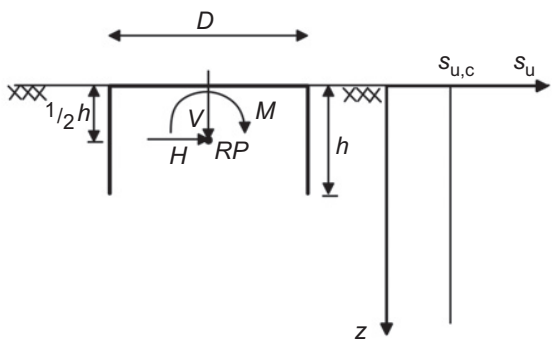

(b)

Fig. 7. Illustration of the two soil profiles considered. (a) Normally consolidated to lightly overconsolidated site (OCR = 1 and 4$)$ with increasing strength $\Delta s_{\mathrm{u}} I \Delta z$ and load applied $2 \mathrm{~h} / 3$ below seabed. (b) Heavily overconsolidated clay $(\mathrm{OCR}=40)$ with constant shear strength $s_{\mathrm{u}, \mathrm{c}}$ and load applied $h / 2$ below seabed

ratio between the cyclic and average load component is quantified as the cyclic-to-total load ratio, $F_{\text {cy }} /\left(F_{\text {cy }}+F_{\text {a }}\right)$, since this quantity conveniently varies between 0 and 1 . Total cyclic capacity refers to the combined capacity from both the average and the cyclic load component, $F_{\mathrm{cy}}+F_{\mathrm{a}}$, analogous to the definition on peak shear stress explained in Fig. 1. The capacity under monotonically increasing loads at standard laboratory test rate, henceforth referred to as static reference capacity, $F_{\mathrm{a}, \mathrm{ref}}=\left[V_{\mathrm{a}, \mathrm{ref}}, H_{\mathrm{a}, \mathrm{ref}}, M_{\mathrm{a}, \mathrm{ref}}\right]$, was computed and used for normalisation of the cyclic capacity for the relevant load component.

Figure 9 shows the normalised cyclic capacity for different cyclic-to-total load ratios as a function of the equivalent number of cycles, $N_{\text {eq }}$. The cyclic capacity reduces as a function of $N_{\text {eq }}$ for all cyclic-to-total load ratios and values of OCR. The figure contains normalised capacities for all three 
Table 1. Undrained DSS shear strength for different OCRs

\begin{tabular}{l|l|l|l}
\hline & \multicolumn{2}{|l|}{$\begin{array}{l}\text { Profile with } \\
\text { increasing shear } \\
\text { strength }\end{array}$} & $\begin{array}{l}\text { Profile with constant shear } \\
\text { strength }\end{array}$ \\
\hline$s_{\mathrm{u}}^{\mathrm{DSS}}$ & $\begin{array}{l}\mathrm{OCR}=1 \\
0 \cdot 21 \sigma_{\mathrm{v}}^{\prime}\end{array}$ & $\begin{array}{l}\text { OCR }=4 \\
1 \cdot 0 \sigma_{\mathrm{v}}^{\prime}\end{array}$ & $\begin{array}{l}\text { OCR }=40 \\
58 \mathrm{kPa}\end{array}$ \\
\hline
\end{tabular}

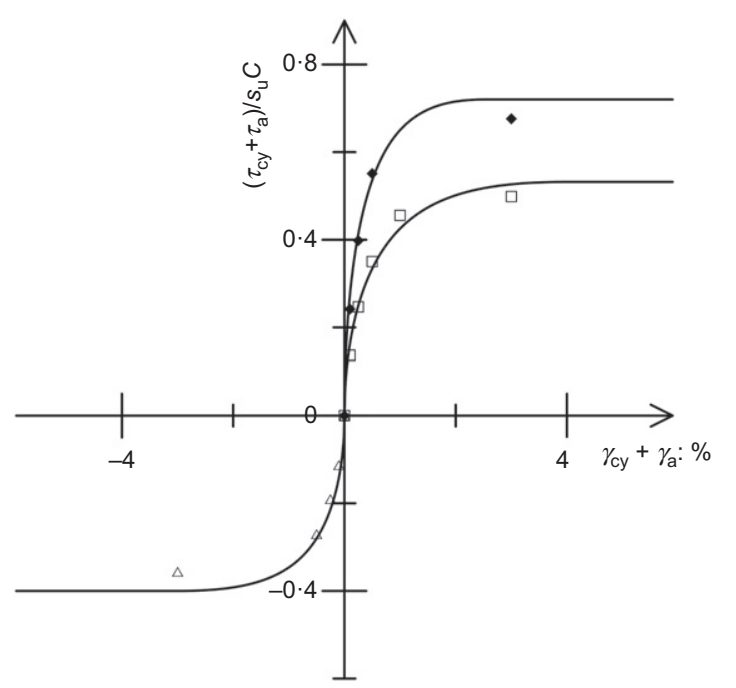

Fig. 8. Triaxial and DSS shear stress-strain curves for Drammen clay OCR $=4, N=10$ and $\tau_{\mathrm{a}}=0$ (contour data shown as points and soil model representations as solid lines)

uniaxial load components $(V, H, M)$. However, the normalised values of the three load components are almost identical and no distinction was made between them to improve the readability. The similarity means that the reduction is nearly independent of the load component for a given $F_{\text {cy }} /\left(F_{\text {cy }}+F_{\mathrm{a}}\right)$ and OCR. As shown in Fig. 9(a), the normalised capacities for $\mathrm{OCR}=1$ and 4 almost coincide. Thus, common trend lines are suggested for the three cyclic-to-total load ratios valid for both $\mathrm{OCR}=1$ and $\mathrm{OCR}=4$. Three separate lines are given for OCR $=40$ in Fig. 9(b). The results in the figures reflect the cyclic behaviour of the Drammen clay and its degradation. The degradation is different for triaxial compression, extension and DSS soil elements for OCR $=1$ and 4 (Andersen et al., 1980). However, the total degradation behaviour computed for the foundation force resultant are similar for OCR $=1$ and 4 when the capacities are normalised by $F_{\text {a,ref }}$ for the relevant OCR.
Figures 9(a) and 9(b) also show that, for OCR $=1$ and 4 , the normalised cyclic capacity is higher than 1 for low values of $N_{\text {eq }}$. This observation agrees with the cyclic behaviour at soil element level and is due to the effect of strain rate (Bjerrum et al., 1958; Richardson \& Whitman, 1963). Cyclic tests are run with a stress cycle period representative for wave loading with a period $T=10 \mathrm{~s}$, which is faster than conventional static laboratory tests. For OCR $=40$, significant degradation is present even in the first cycle.

\section{FAILURE ENVELOPES FOR COMBINED STATIC AND CYCLIC GENERAL LOADING \\ Effect of cyclic loading and shear strength profile}

In line with the trend revealed in the previous section, the size of the failure envelopes depends on the number of equivalent cycles, $N_{\text {eq }}$ and the ratio of cyclic-to-total load. Fig. 10 shows an example of failure envelopes for a skirted foundation with $h=D=10 \mathrm{~m}$ and the soil profile with increasing shear strength given by $\mathrm{OCR}=1$. The failure envelope is plotted in the $H V$ load plane (for $M=0$ ) for different $N_{\text {eq }}(=1,10$ and 100$)$ and $F_{\text {cy }} /\left(F_{\text {cy }}+F_{\mathrm{a}}\right)(=1,2 / 3$, $1 / 2)$. The yield surface contracts for increasing $N_{\text {eq }}$ for all $F_{\text {cy }} /\left(F_{\text {cy }}+F_{\text {a }}\right)$.

Failure envelopes are often presented in a normalised form. This is convenient since the normalised envelopes become general envelopes applicable to various foundation sizes. Fig. 10 shows the failure envelopes from the same cases normalised by the maximum capacities $V_{\max }, H_{\max }$ and $M_{\max }$, with out-of-plane load equal to zero. Normalised failure envelopes from three other analyses are also included in Fig. 11. These represent the results of two analyses with increasing shear strength profiles representing $\mathrm{OCR}=4$, $N_{\text {eq }}=1, \quad F_{\text {cy }} /\left(F_{\text {cy }}+F_{\mathrm{a}}\right)=2 / 3 \quad$ and $\quad$ OCR $=4, \quad N_{\text {eq }}=10$, $F_{\text {cy }} /\left(F_{\text {cy }}+F_{\mathrm{a}}\right)=1$, and one analysis with constant shear strength profile representing $\mathrm{OCR}=40, \quad N_{\mathrm{eq}}=10$, $F_{\text {cy }} /\left(F_{\text {cy }}+F_{\mathrm{a}}\right)=1$. The first case has the highest shear strength gradient with depth in this study and a higher cyclic strength than the static shear strength due to the beneficial combination of cyclic and average load. This means that the plot includes cases from both ends of the range considered in the study. The normalised envelopes in the three load planes ( $H V, M V$ and $H M$ plane) show a visible variation, but are tightly grouped.

The normalised failure envelopes for constant shear strength were found to differ from the envelopes for increasing shear strength profiles.

The different reference point for the two profiles is obviously one reason for the different shape of the failure envelopes. It was orignally an aim of the study to unify the normalised failure envelopes for constant and increasing

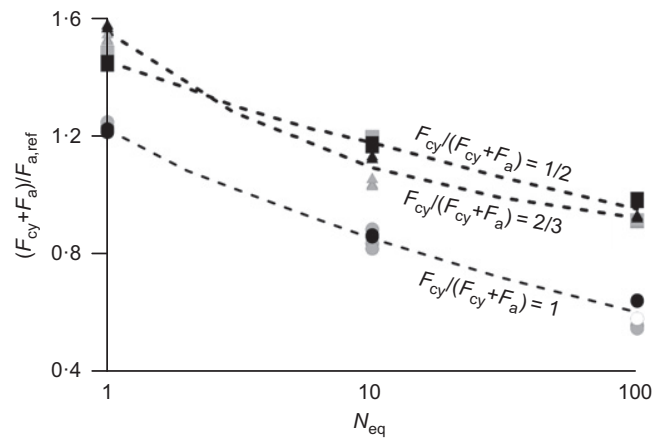

(a)

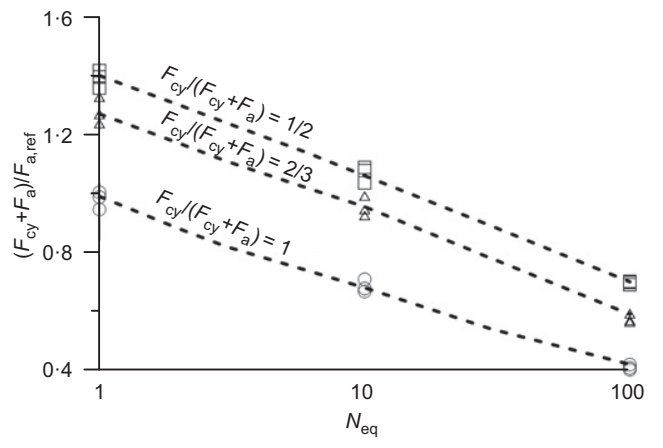

(b)
- $F_{\mathrm{cy}} /\left(F_{\mathrm{cy}}+F_{\mathrm{a}}\right)=1, \mathrm{OCR}=1$

- $F_{\text {cy }} /\left(F_{c y}+F_{\mathrm{a}}\right)=2 / 3, \mathrm{OCR}=1$

$F_{\text {cy }} /\left(F_{\text {cy }}+F_{\mathrm{a}}\right)=1 / 2$, OCR $=1$

$F_{\mathrm{cy}} /\left(F_{\mathrm{cy}}+F_{\mathrm{a}}\right)=1, \mathrm{OCR}=4$

$F_{c y} /\left(F_{c y}+F_{a}\right)=2 / 3$, OCR $=4$

$F_{\text {cy }} /\left(F_{\text {cy }}+F_{\mathrm{a}}\right)=1 / 2, \mathrm{OCR}=4$

$F_{\mathrm{cy}} /\left(F_{\mathrm{cy}}+F_{\mathrm{a}}\right)=1, \mathrm{OCR}=40$

$F_{\mathrm{cy}} /\left(F_{\mathrm{cy}}+F_{\mathrm{a}}\right)=2 / 3, \mathrm{OCR}=40$

$F_{\text {cy }} /\left(F_{\text {cy }}+F_{\mathrm{a}}\right)=1 / 2, \mathrm{OCR}=40$

Fig. 9. Normalised cyclic uniaxial capacity for $V, H$ and $M$ loading, different cyclic-to-total load ratios as function of equivalent number of cycles, $N_{\text {eq }}$ : (a) OCR = 1 and 4; (b) OCR $=40$ 


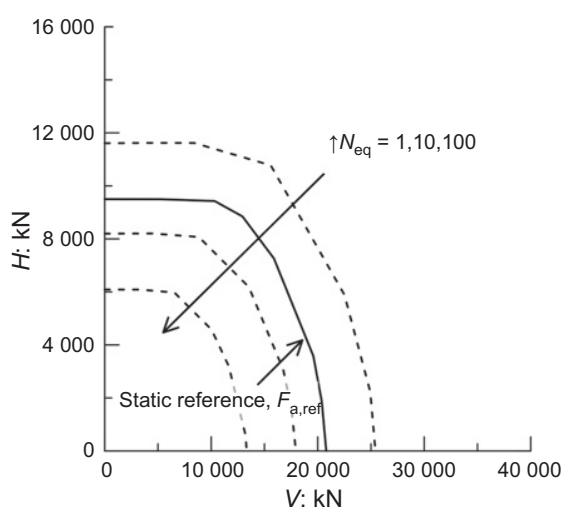

(a)

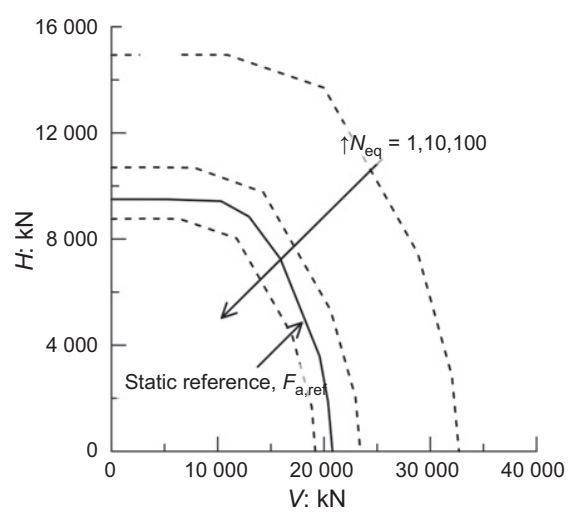

(b)

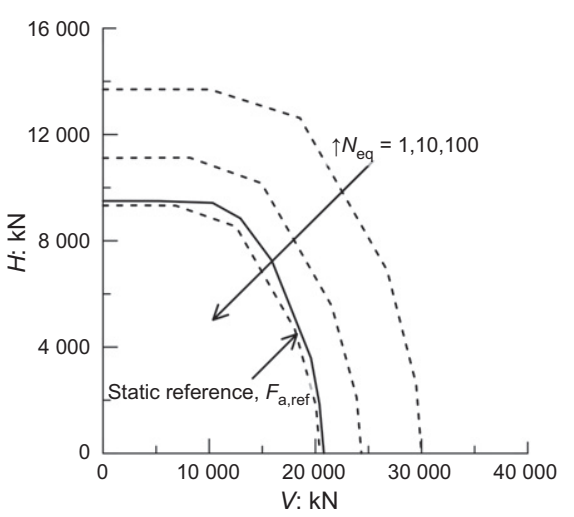

(c)

Fig. 10. Failure envelopes for different $N_{\text {eq }}$ in the $H V$ plane $(M=0)$ for a skirted foundation geometry, $h=D=10 \mathrm{~m}$ and increasing shear strength with depth $(\mathrm{OCR}=1)$. The cyclic-to-total load ratio is constant within a figure: (a) $F_{\mathrm{cy}} /\left(F_{\mathrm{cy}}+F_{\mathrm{a}}\right)=1 ; \quad(\mathrm{b}) F_{\mathrm{cy}} /\left(F_{\mathrm{cy}}+F_{\mathrm{a}}\right)=2 / 3$; (c) $F_{\text {cy }} /\left(F_{\text {cy }}+F_{\mathrm{a}}\right)=1 / 2$

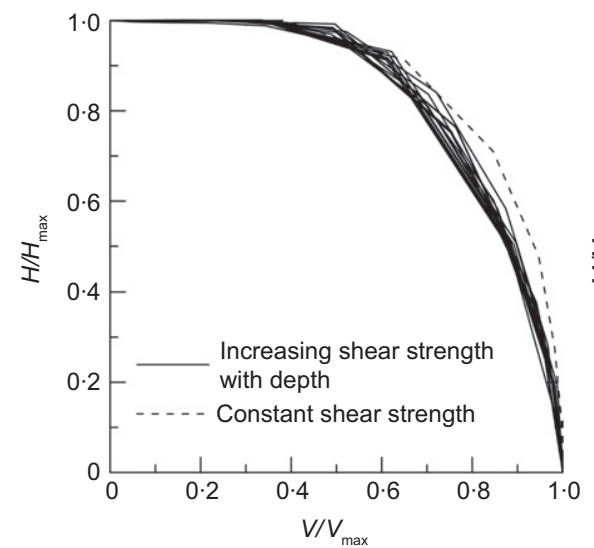

(a)

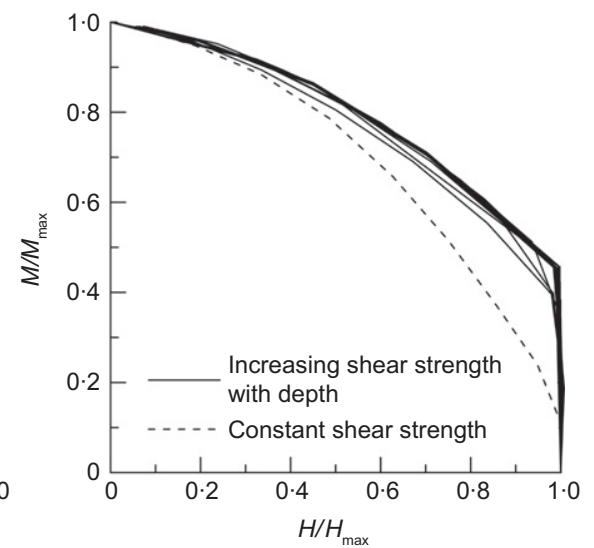

(b)

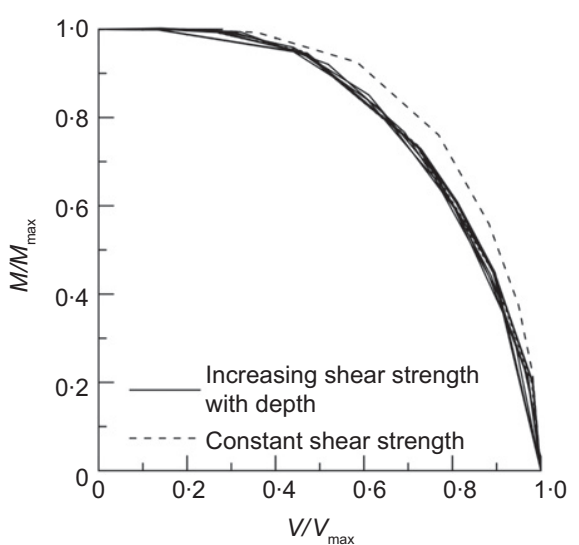

(c)

Fig. 11. Normalised failure envelopes in all three load planes for the cases considered in Fig. 10, and in addition two envelopes for OCR $=4$ with high shear strength gradient with depth and one for $\mathrm{OCR}=\mathbf{4 0}$ with constant shear strength

shear strength profiles by adjustig the reference point depending on profile and aspect ratio in line with the work by Fan et al. (2012). However, the results from the FEA showed that such a unification was only partly possible since the envelopes did not coincide for the whole load range. The idea of a complete unification of all failure envelopes, by adjusting the reference point individually for all cases considered, was therefore abandoned. The load reference points were still kept at two different depths for the two different profiles, as defined earlier in the paper. This ensured that the maximum horizontal load was located on the horizontal load axis $(M=0)$ as required by the scaling procedure explained later in the paper.

The agreement between the normalised envelopes for increasing shear strength profiles is sufficient to consider the shape to be similar for the range of $N_{\text {eq }}$ considered in the study (1-100). This implies that the shape representative for $N_{\text {eq }}=1$ can be scaled to other $N_{\text {eq }}$. An important assumption in the analyses is that the global $N_{\mathrm{eq}}$ is uniform for all three loading directions. However, the approach may be a bit too conservative if one loading component dominates the degradation process while the maximum load to be assessed by the failure envelope has a very different load combination.

The variations in $N_{\text {eq }}$ and $F_{\text {cy }} /\left(F_{\text {cy }}+F_{\mathrm{a}}\right)$ are implemented in the analyses by defining the relevant cyclic stress-strain relation and cyclic shear strength profile. The results are therefore comparable with existing studies on the effect of shear strength heterogeneity. The extensive study by Gourvenec \& Barnett (2011) supports the observations that the normalised failure envelopes for skirted foundations are placed within a narrow band in the $H V$ plane and the $M V$ plane. However, Gourvenec \& Barnett (2011) observe greater effect on the soil strength homogeneity in the $H M$ plane. This observation is still not in disagreement with the present study, since Gourvenec \& Barnett (2011) also consider shear strength profiles with higher shear strength at the seabed than the profiles considered herein.

\section{Load axis symmetry of the failure envelopes}

The undrained response in the $H V$ plane and $M V$ plane is symmetric around all axes, assuming full reversed end bearing for tension loads (Mana et al., 2013). Hence, one quadrant gives a full description of the full $360^{\circ}$ failure envelope. However, the envelope in the $H M$ plane is symmetric only around the horizontal axis, and it is therefore necessary to show $180^{\circ}$ of the failure envelope to describe the response for all combinations. This observation agrees with the findings in the experimental and numerical studies by Martin (1994), Gourvenec \& Barnett (2011) and Ibsen et al. (2014), which find the failure envelope in the $H M$ plane to be non-symmetric. The lack of symmetry is related to the different modes of failure evolving for load combinations in the different quadrants. Fig. 12 shows the $360^{\circ}$ normalised 


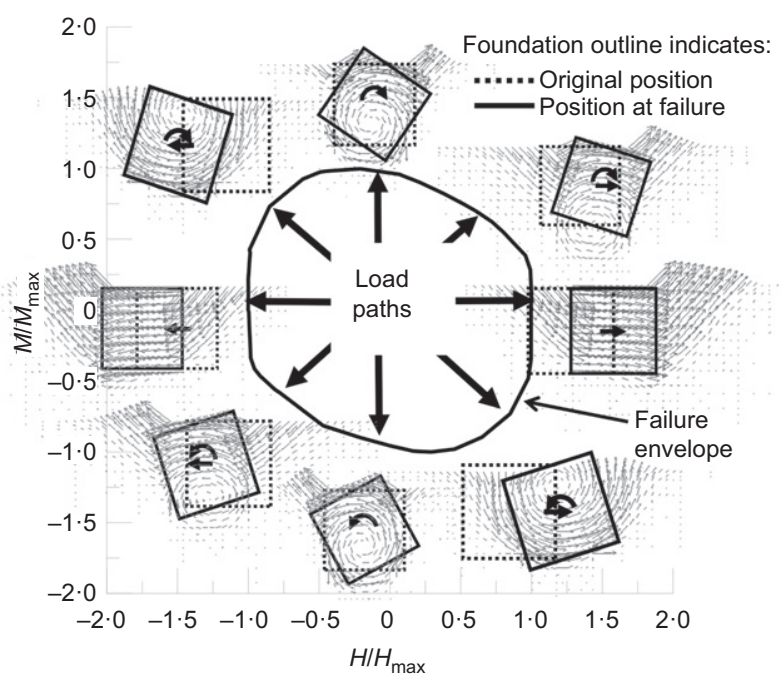

Fig. 12. Three-hundred-and-sixty-degree failure envelope in the $H M$ plane and outline of the foundation movement at failure for different radial load paths

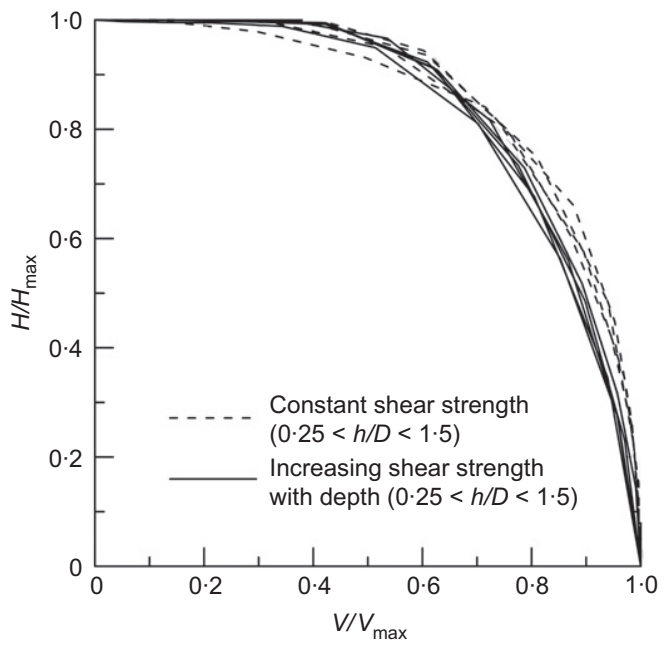

(a) failure envelope in the $H M$ plane for a skirted foundation with $h / D=1 \quad(h=10 \mathrm{~m}, \quad D=10 \mathrm{~m}), \quad$ OCR $=1$, $F_{\mathrm{cy}} /\left(F_{\mathrm{a}}+F_{\mathrm{cy}}\right)=1 / 2$ and $N_{\mathrm{eq}}=1$. The modes of failure for different combinations of $H M$ loading are also indicated in the figure. The convenience of the chosen load reference point is nicely illustrated in the figure as it intuitively relates the different quadrants to the different failure modes.

\section{Effect of foundation geometry}

The failure envelopes from analyses of skirted foundations with four different aspect ratios, $h / D$, are shown in Figs 13 and 14. The variation in aspect ratio was obtained by varying the skirt depth, $h$, while the diameter, $D=10 \mathrm{~m}$, was kept constant. The figures include failure envelopes for profiles with increasing and constant shear strength. In agreement with Gourvenec \& Barnett (2011), it was found that the effect of aspect ratio was negligible in the $H V$ plane, and visible but still limited to a relatively narrow band in the $V M$ plane. Envelopes in the positive quadrant of the $H M$ plane show more significant dependency. The range for which the maximum horizontal load is independent of the moment load increases as the aspect ratio reduces for both constant

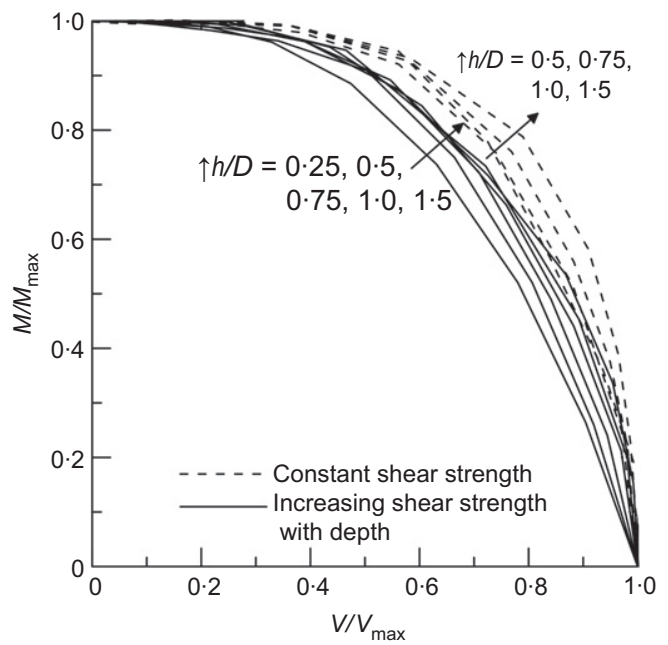

(b)

Fig. 13. Failure envelopes in the $H V$ load plane and $M V$ load plane for different foundation geometries (aspect ratios) in soil profiles with constant and increasing shear strength with depth

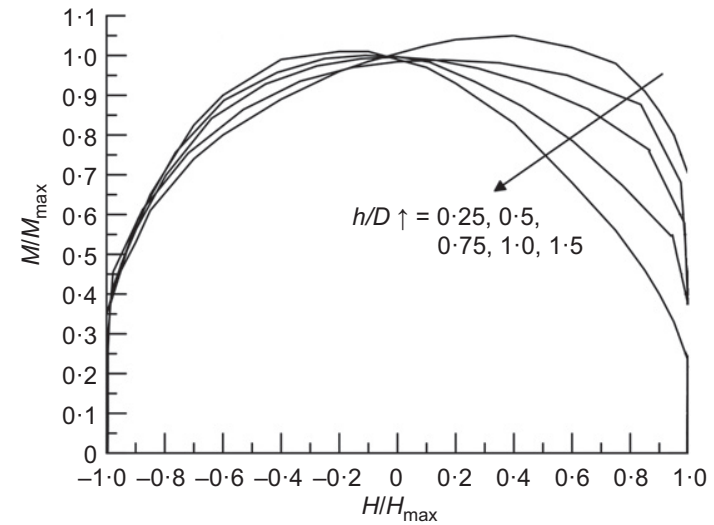

(a)

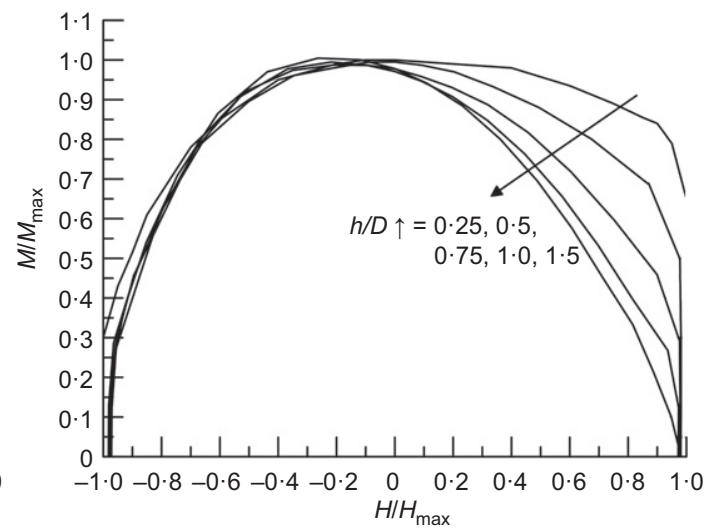

(b)

Fig. 14. Failure envelopes for different foundation geometries in (a) increasing shear strength profiles and (b) constant shear strength profiles 


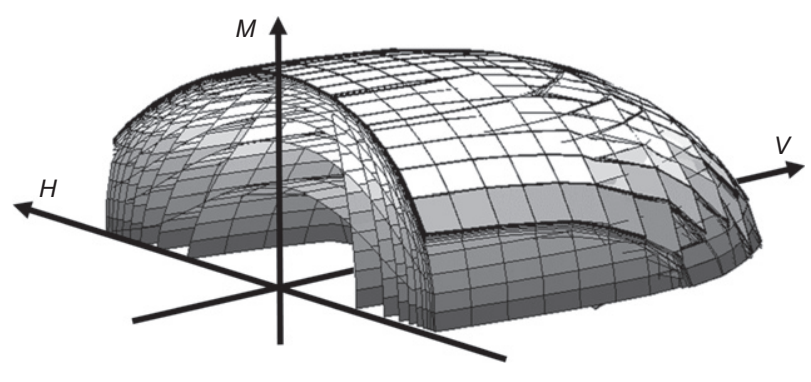

Fig. 15. Example of surface displacement contours in a 3D load space for a skirted foundation

and increasing shear strength profiles. The figure also shows the non-symmetric nature of the failure envelope.

\section{DISPLACEMENT CONTOURS}

More information can be included in the diagrams by adding contours of displacement. The diagrams can then be used to determine the displacement and the stiffness for combined loading in addition to the capacity. It was convenient to normalise the vertical and horizontal displacement with the foundation diameter $(D)$ and the sum of the foundation diameter and skirt depth $(D+h)$. For cases with similar foundation aspect ratio, similar shear strength profile and soil stress-strain behaviour, the normalisation method brings the curves within a relatively narrow band. The moment-rotation curves coincide well without normalising the rotation if the moment load is normalised by the maximum moment.

A great number of analyses were carried out in HVMCap to establish a database of diagrams with normalised displacement response to general cyclic loading. For the specific displacement results included in the paper, 3D FEAs were carried out to ensure the reliability of the results. A foundation geometry of $h=10 \mathrm{~m}$ and $D=10 \mathrm{~m}$ was used as the base case for all the diagrams in the database. As an example of this database, Fig. 15 shows a 3D illustration of surface contours in a 3D load space based on HVMCap analyses. Only one-quarter of the full 3D space is shown for clarity. A simple Matlab (Mathworks, 2017) routine extracts values from these diagrams for a specified load path and provides curves of normalised load-displacement response. By plotting 2D cross-sections from the $3 \mathrm{D}$ surfaces, the contours can be read out of the diagrams manually. The diagrams can be used for approximate preliminary calculations of foundation stiffness. Fig. 16 shows 2D crosssections of the response where the out-of-plane load is zero for a foundation geometry $h / D=1$, linearly increasing shear strength and soil stress-strain response representing Drammen clay with $\mathrm{OCR}=4, N_{\mathrm{eq}}=10$ and cyclic-to-total load, $F_{\text {cy }} /\left(F_{\text {cy }}+F_{\mathrm{a}}\right)=1$. The normalised displacements that correspond to the in-plane loads are drawn as contour lines. The values of the displacement contours are given below each figure. The figures show that the displacement contours adapt to the shape of the failure envelope when the mobilisation increases. However, at lower mobilisation, the displacements and rotations show a quite different interaction with the loads in other directions, for example the dependency of rotational contours on the vertical load.

\section{USE OF DATABASE}

The displacement diagrams are accompanied by simplified scaling procedures that make a set of diagrams (e.g. Fig. 16) applicable to a wider range of conditions. The scaling procedures relate the contours in a set of diagrams to (a) foundations with different aspect ratio (within the range of $0.25<h / D<1 \cdot 5)$

(b) foundations in clay with different load-displacement response (e.g. due to different stress-strain soil response)

(c) different levels of cyclic degradation.

The latter, effect of cyclic degradation, is accounted for by utilising the information in Fig. 9 (effect of $N_{\text {eq }}$ ). The first two scaling procedures are somewhat more complex and are explained in the following sections.

\section{Scaling displacement for general loading based on response} along the main axes

Foundations in soil with different soil stress-strain behaviour will have different normalised load-displacement curves. The difference will affect the displacement response for any load combination. In addition, differences in the shear strength profiles and foundation aspect ratio may also change the normalised load-displacement curve even if the soil's stress-strain response is the same. To accurately account for these changes, it is necessary to run a full set of analyses along different load paths to establish a new diagram. However, as a simplification, it is possible to account for the difference in load-displacement response by updating displacement diagrams based on a scaling function. The parameters in the scaling function are defined through the load-displacement response in the three uniaxial load directions, and the defined set of parameters will relate to a specific problem. The procedure makes it possible to describe displacements in a complete 3D load space based on information from three uniaxial response curves. The procedure requires a base diagram with displacement contours denoted $u_{\mathrm{v}}, u_{\mathrm{h}}$ and $\theta$. In this paper, Fig. 16 will serve as the base diagram. The corresponding scaled displacements are henceforth denoted $u_{\mathrm{v}}^{*}, u_{\mathrm{h}}^{*}$ and $\theta^{*}$. The two sets of displacements are related through the scaling function $\zeta$ and can be written as

$$
\begin{aligned}
& u_{\mathrm{v}}^{*}=\zeta_{\mathrm{v}} u_{\mathrm{v}} \\
& u_{\mathrm{h}}^{*}=\zeta_{\mathrm{h}} u_{\mathrm{h}} \\
& \theta^{*}=\zeta_{\theta} \theta
\end{aligned}
$$

where $\zeta_{\mathrm{v}}, \zeta_{\mathrm{h}}, \zeta_{\theta}$ are expressed generally as $\zeta$ for all the three $\mathrm{DOF}$ as

$$
\zeta=\lambda+\beta_{1}\left(\frac{u}{u_{\mathrm{f}}}\right)+\beta_{2}\left[\frac{2 \sqrt{u / u_{\mathrm{f}}}}{1+\left(u / u_{\mathrm{f}}\right)}\right]
$$

where $\lambda, \beta_{1}, \beta_{2}$ are curve-fit parameters; $u$ is one of the displacement variables $\left(u_{\mathrm{v}}, u_{\mathrm{h}}\right.$ and $\left.\theta\right)$; and $u_{\mathrm{f}}$ is the normalisation reference for the displacement component under consideration. The scaling function is simple but flexible. $\lambda$ gives the possibility of applying a constant scaling of the curve. $\beta_{1}\left(u / u_{\mathrm{f}}\right)$ gives the possibility of linear scaling as a function of the displacement $u$ normalised by the failure displacement $u_{\mathrm{f}}$, while the latter part, $\beta_{2}\left\{2 \sqrt{u / u_{\mathrm{f}}} /\left[1+\left(u / u_{\mathrm{f}}\right)\right]\right\}$ adds non-linearity to the scaling function. The scaling function has the value, $\zeta=\lambda+\beta_{1}+\beta_{2}$, when $u / u_{\mathrm{f}}=1$. The shape of the scaling function and the influence of some of the parameters are shown in Fig. 17. In design situations, engineers face large variations in soil profiles and soil stress-strain behaviour. To make the determination of function parameters efficient, an optimisation routine was written in Matlab (Mathworks, 2017) to automate this fitting. However, the parameters may also be determined by trial and error. Fig. 18 shows normalised load-displacement curves from uniaxial load paths in Fig. 16 


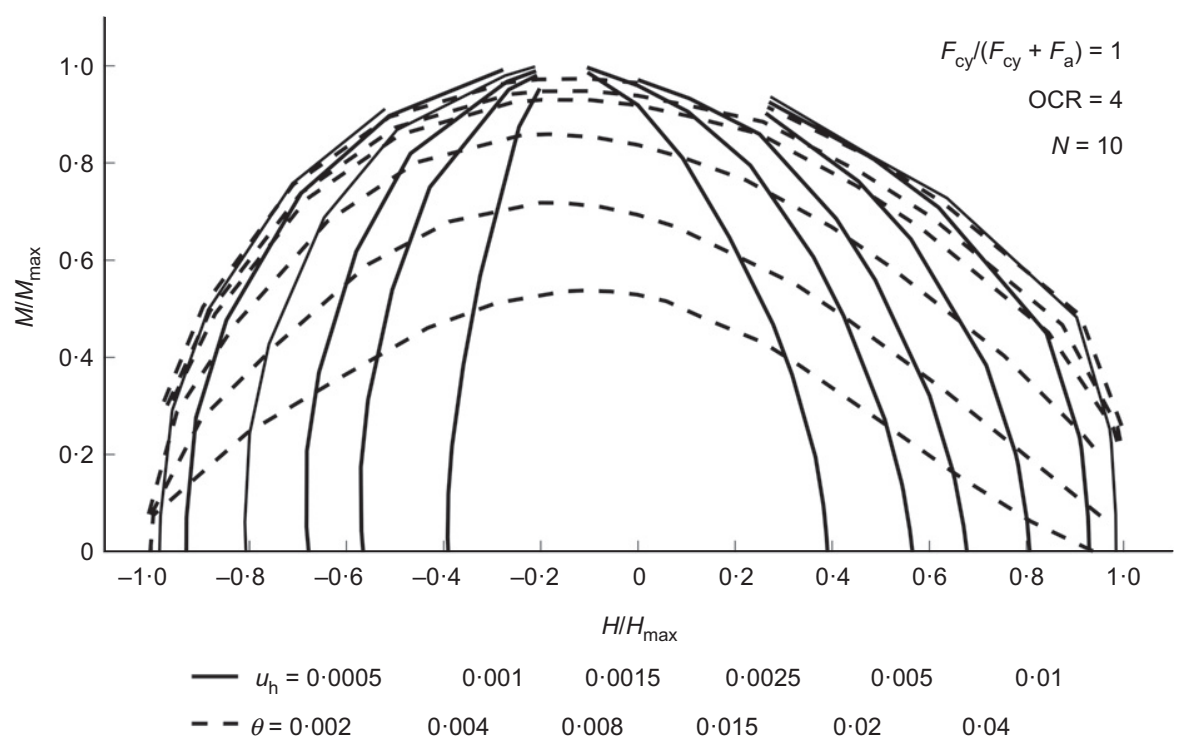

(a)

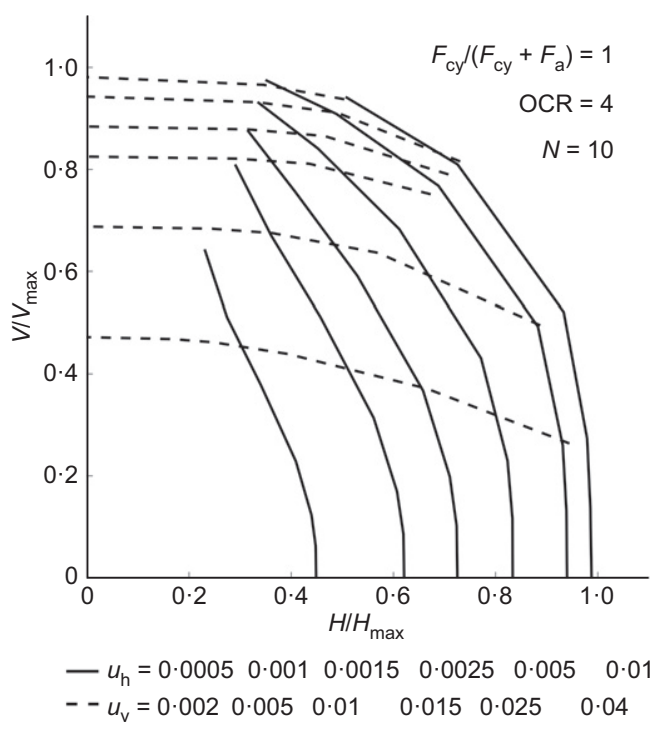

(b)

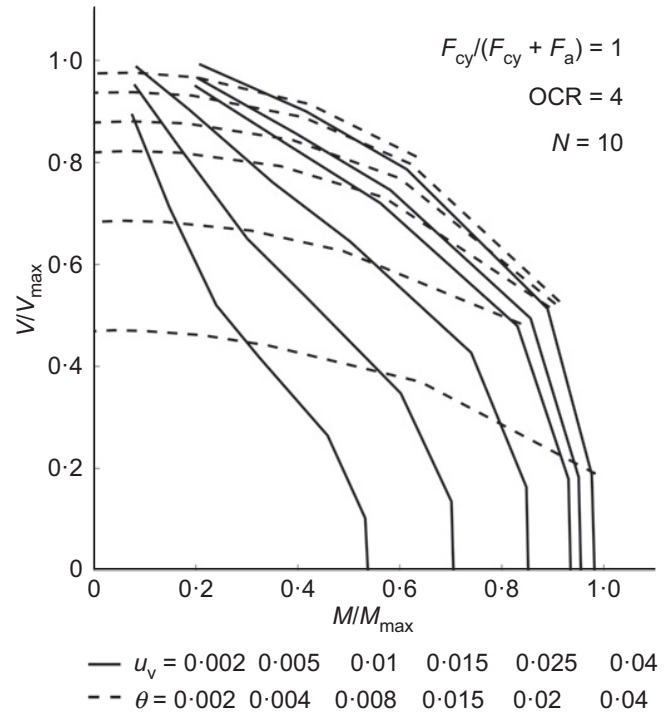

(d)

Fig. 16. Normalised displacement contours for different cyclic-to-total load ratios in the three load planes with out-of-plane load equal to zero for a skirted foundation with aspect ratio $h / D=1$, linear increasing shear strength, Drammen clay with $O C R=4$ and $N_{\text {eq }}=10$ (the value of the normalised contours are given below each figure): (a) $H M$ load plane; (b) $H V$ load plane; (c) $M V$ load plane

and how these are scaled by equation (1) to fit the response from two examples. The responses for these examples were computed by 3D FEA. A set of scaling parameters was established for each example. Example 1 represents a foundation with aspect ratio $h / D=1 \cdot 0$, increasing shear strength with depth and OCR $=4, N_{\text {eq }}=10$ and $F_{\text {cy }} /\left(F_{\text {cy }}+F_{\mathrm{a}}\right)=0 \cdot 67$. Example 2 is relevant for the backcalculation of a model test considered later in the paper. The foundation aspect ratio was $h / D=0 \cdot 25$, and the bottom boundaries were located at the depth $0 \cdot 53 \mathrm{D}$. The stress-strain behaviour represented a Moum clay with $\mathrm{OCR}=3.4$, $N_{\text {eq }}=10, F_{\text {cy }} /\left(F_{\text {cy }}+F_{\mathrm{a}}\right)=1$, and the shear strength profile was modelled according to the model test. The model test geometry is shown later in Fig. 22, and more details of the test and the Moum clay are given in the section considering the back-calculation. The scaling parameters $\left(\lambda, \beta_{1}, \beta_{2}, u_{\mathrm{f}}\right)$ were determined for the two examples and the values are given in Table 2. With the parameters defined for $\zeta_{\mathrm{V}}, \zeta_{\mathrm{h}}$ and $\zeta_{\theta}$, the displacements for any given general load path can be scaled by equation (1). Fig. 19 shows the accuracy of the procedure estimating the response of a general load path for example 1. The load ratio applied to Fig. 16(b) was $h^{\prime} / v^{\prime}=0.89$ where $h^{\prime}=H / H_{\max }$ and $v^{\prime}=V / V_{\max }$. The loaddisplacement response computed directly by 3D FEA for the exact load path is shown for comparison in Fig. 19. The agreement is good. Several similar comparisons were carried out to investigate the reliability of the scaling procedure for different load paths and to account for different soil stressstrain behaviour. Good agreement was observed in these comparisons.

\section{Scaling displacement diagrams according to foundation aspect ratio}

The effect of aspect ratio in the $H V$ plane and $M V$ plane are considered sufficiently small to be neglected. Based on the HVMCap analyses behind Fig. 14, a set of diagrams was derived for scaling displacement contours in the $H M$ plane to the foundation aspect ratio of interest. It was chosen to base the scaling on values to be added to the basis response 


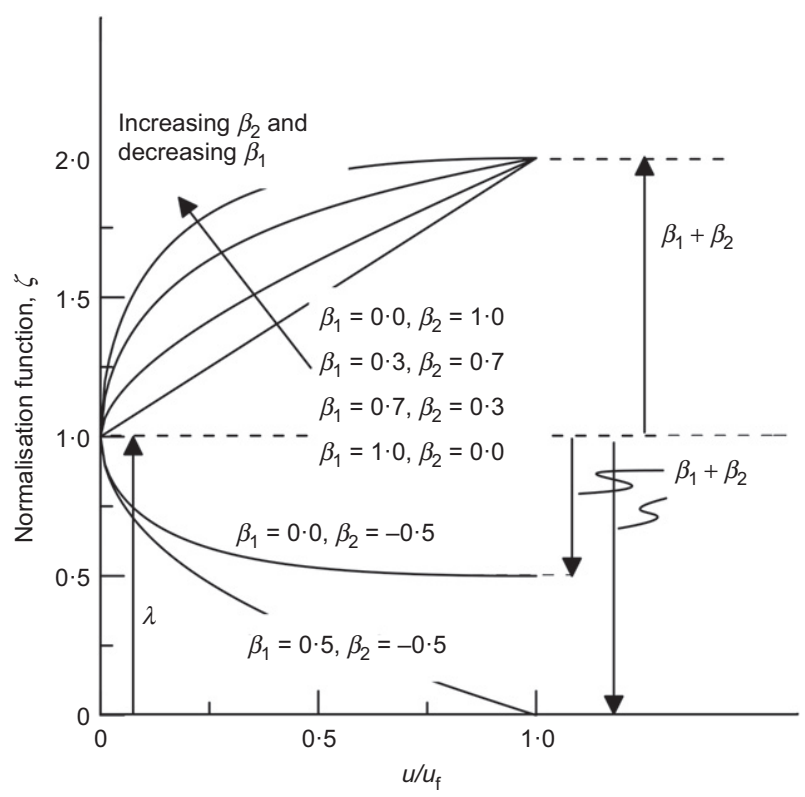

Fig. 17. Illustration of the effect of the parameters in the scaling function $(\lambda=1)$

diagrams in Fig. 16. For the sake of simplicity, these addends were

(a) based on changes in contours at high mobilisation (failure)

(b) given as a function of the load component perpendicular to the displacement direction (which means that changes in horizontal displacement contours were related solely to normalised moment load, and vice versa).

For other cross-sections along the vertical load axis, the horizontal load and moment can be normalised by the maximum loads in the respective cross-section, since the shape of the failure envelope in the $H M$ plane is relatively constant with the vertical load (Gourvenec \& Barnett, 2011). Four diagrams of addends have been established to scale the response diagrams in Fig. 16 to diagrams representing other foundation aspect ratios. Two diagrams are given for linearly increasing shear strength profiles, and two diagrams are given for constant shear strength profiles. The diagrams are shown in Fig. 20 and give addends expressed as normalised load values $\left(g_{\mathrm{h}}, g_{\theta}\right)$, which should be added to the load value in the basis diagrams (e.g. Fig. 16). Each contour line (horizontal displacement, $u_{\mathrm{h}}$, and rotation, $\theta$ ) will then be scaled (or translated) in the normalised load space from its original position in load space to the updated position in load space, based on the addends $g_{\mathrm{h}}$ and $g_{\theta}$. In normalised form, the scaling or update is simply described as

$$
\begin{aligned}
& h_{\text {upd }}^{\prime}\left(m^{\prime}, u_{\mathrm{h}}\right)=h^{\prime}\left(m^{\prime}, u_{\mathrm{h}}\right)+g_{\mathrm{h}}\left(m^{\prime}, h / D\right) \\
& m_{\text {upd }}^{\prime}\left(h^{\prime}, \theta\right)=m^{\prime}\left(h^{\prime}, \theta\right)+g_{\theta}\left(h^{\prime}, h / D\right)
\end{aligned}
$$

where $h^{\prime}=H / H_{\max }, m^{\prime}=M / M_{\max }$ and $h / D$ is the foundation aspect ratio. To demonstrate the accuracy of the suggested scaling procedure, Fig. 21 compares two response diagrams. Fig. 21(a) shows a diagram scaled from $h / D=1$ to $h / D=0 \cdot 25$. The contours were scaled (or translated) from their original position in Fig. 16(a) based on equation (3) and the addends $g_{\mathrm{h}}$ and $g_{\theta}$ in Fig. 20(a). Fig. 21(b) shows a response diagram with the displacement contours based directly on 3D FEA with correct foundation geometry. One original contour $(\theta=0 \cdot 008)$ from Fig. 16(a) is included in Fig. 21(a) for illustration. The

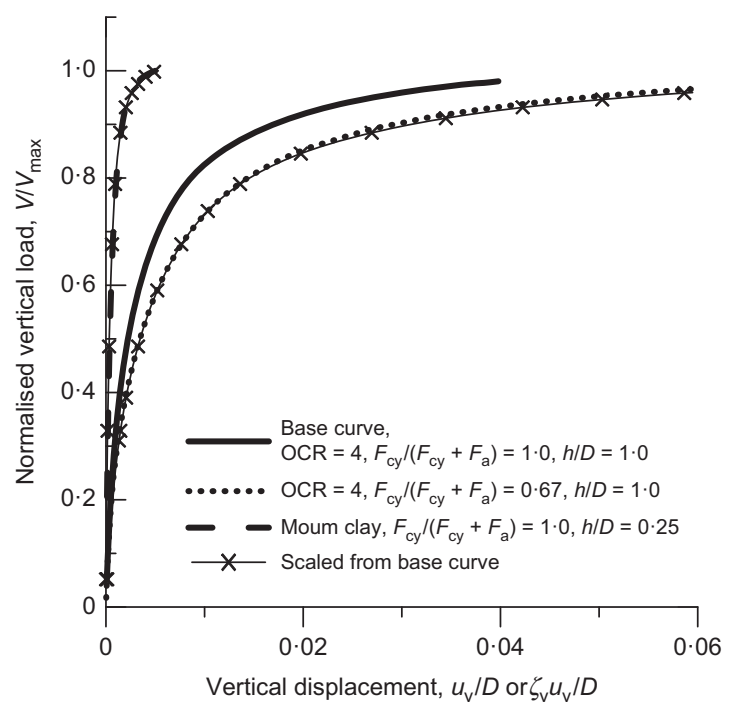

(a)

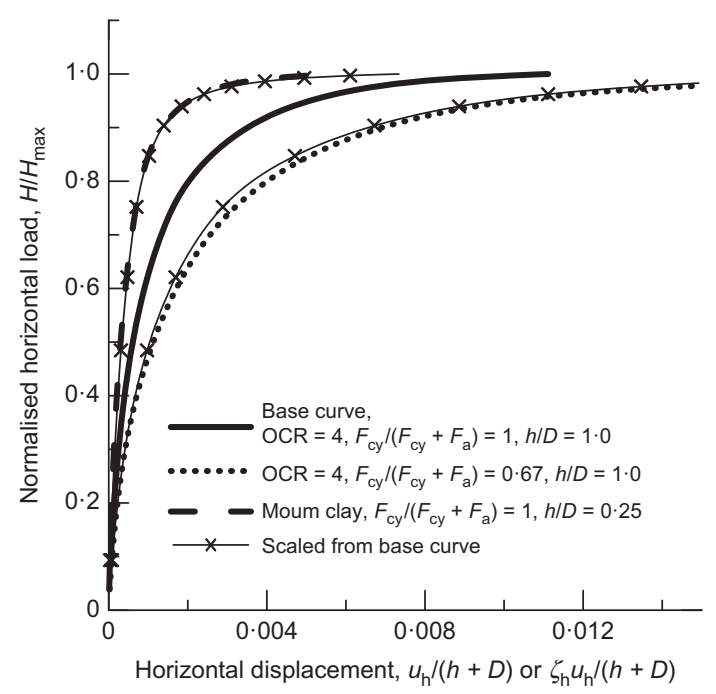

(b)

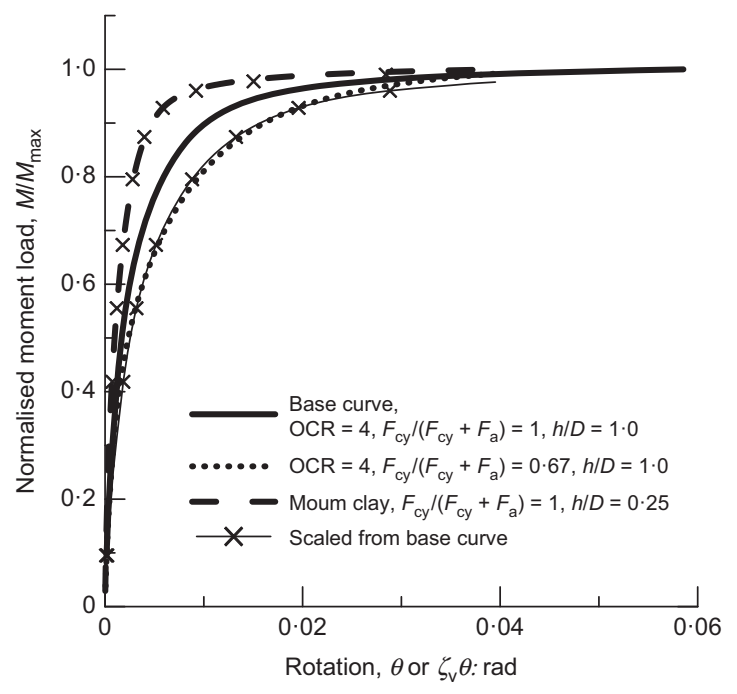

(c)

Fig. 18. Normalised load-displacement curves scaled for pure horizontal, vertical and moment loading

same contour is shown in Figs 21(a) and 21(b) after scaling. The example shows that the simplified scaling laws reflect the most important change, that is the expansion of the diagram to higher combinations of positive horizontal and moment load. 
Table 2. Parameter values for displacement scaling

\begin{tabular}{|c|c|c|c|c|c|}
\hline \multirow[t]{2}{*}{ Example case } & \multirow[t]{2}{*}{$\begin{array}{l}\text { Displacement } \\
\text { component }\end{array}$} & \multicolumn{4}{|c|}{$\begin{array}{l}\text { Parameters in the scaling } \\
\text { function }\end{array}$} \\
\hline & & $\lambda$ & $\beta_{1}$ & $\beta_{2}$ & $u_{\mathrm{f}}$ \\
\hline $\begin{array}{l}\mathrm{OCR}=40, N_{\mathrm{eq}}=10, F_{\mathrm{cy}} /\left(F_{\mathrm{cy}}+F_{\mathrm{a}}\right)=2 / 3, h / D=1 \cdot 0, \text { increasing shear strength } \\
\text { with depth } \\
\text { Moum clay, } N_{\mathrm{eq}}=10, F_{\mathrm{cy}} /\left(F_{\mathrm{cy}}+F_{\mathrm{a}}\right)=1, h / D=0 \cdot 25, \text { model test boundaries and } \\
\text { shear strength profile }\end{array}$ & $\begin{array}{l}\zeta_{\mathrm{v}} \\
\zeta_{\mathrm{h}} \\
\zeta_{\theta} \\
\zeta_{\mathrm{v}} \\
\zeta_{\mathrm{h}} \\
\zeta_{\theta}\end{array}$ & $\begin{array}{l}1 \cdot 40 \\
1 \cdot 60 \\
1 \cdot 50 \\
0 \cdot 20 \\
0 \cdot 80 \\
0 \cdot 80\end{array}$ & $\begin{array}{l}0 \cdot 80 \\
1 \cdot 00 \\
0 \cdot 20 \\
0 \cdot 04 \\
1 \cdot 30 \\
1 \cdot 30\end{array}$ & $\begin{array}{r}0 \cdot 40 \\
0 \cdot 45 \\
0 \cdot 10 \\
-0 \cdot 14 \\
-0 \cdot 90 \\
-0 \cdot 80\end{array}$ & $\begin{array}{l}0 \cdot 10 \\
0 \cdot 06 \\
0 \cdot 45 \\
0 \cdot 06 \\
0 \cdot 02 \\
0.07\end{array}$ \\
\hline
\end{tabular}

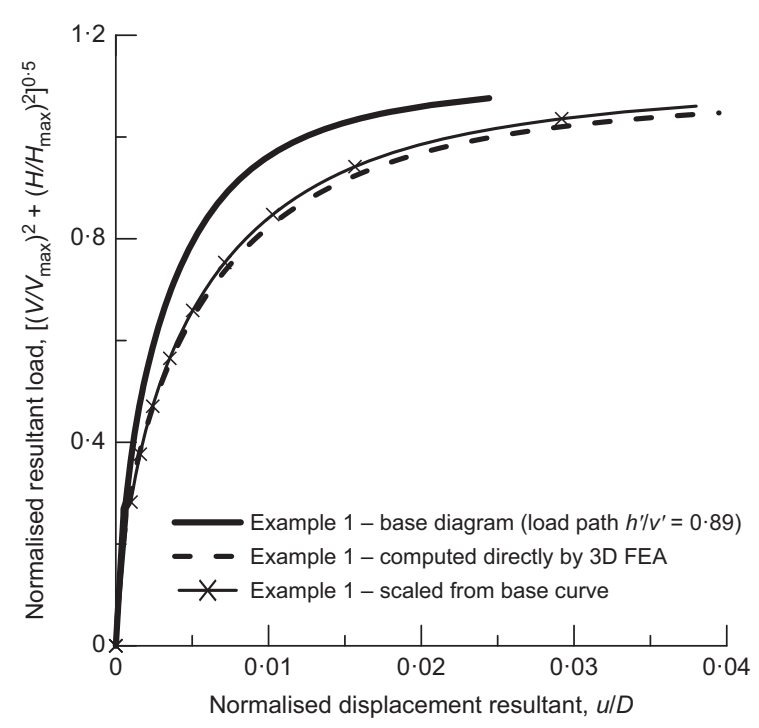

Fig. 19. Load-displacement responses based on the described procedure and computed response by FEA for the exact load path

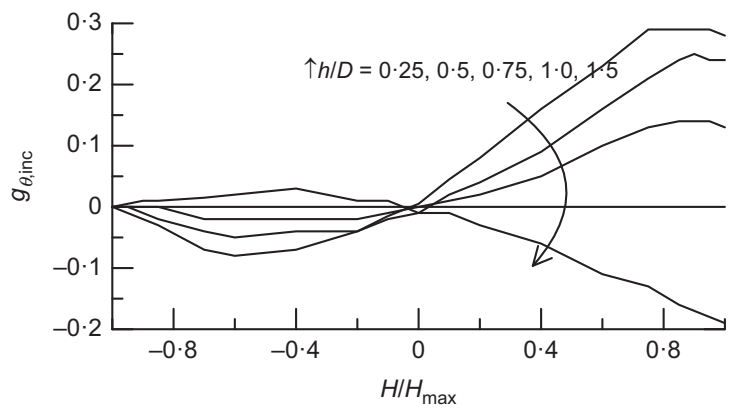

(a)

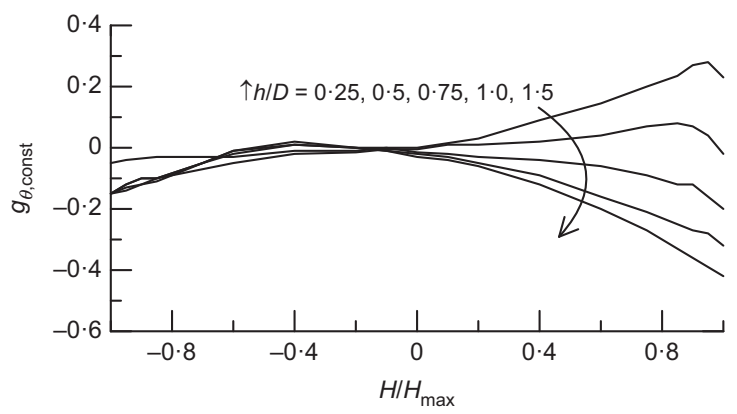

(c)
The prediction of displacements will therefore be more accurate close to failure than at low mobilisation levels. However, the accuracy of the scaling procedure reduces when the difference between the 'new' aspect ratio and the original aspect ratio increases. The example demonstrates scaling to an aspect ratio of 0.25 from $1 \cdot 0$, which is the largest difference possible with the data given herein.

\section{Example: back-calculation of model test}

A model test was back-calculated to demonstrate the usage and the accuracy of the database and the procedure. The model test described in Dyvik et al. (1989) and Andersen et al. (1989) was set up to verify the NGI procedure prior to the design of the Troll A GBS (Skjaeveland et al., 1994). As described in Skau \& Jostad (2014), the test is also comparable to a monopod skirted foundation for an offshore wind turbine. The model test geometry, shown in Fig. 22, consists of a circular foundation partly embedded in clay. The clay (from Moum in Norway) was re-consolidated by a uniform vertical stress. After consolidation, swelling was prevented by closing the drainage valves and covering the top of the sample by an oil film. During testing, the vertical effective

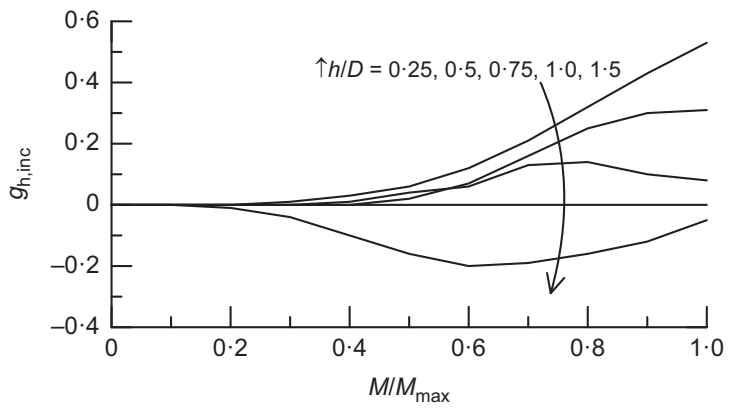

(b)

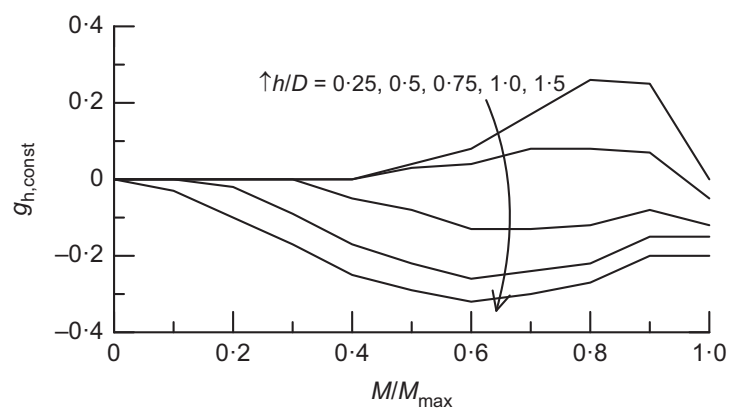

(d)

Fig. 20. Addends $g_{\theta}$ and $g_{\mathrm{h}}$ for scaling of response diagrams to relevant foundation aspect ratio for (a), (b) linearly increasing shear strength and (c), (d) constant shear strength profile 


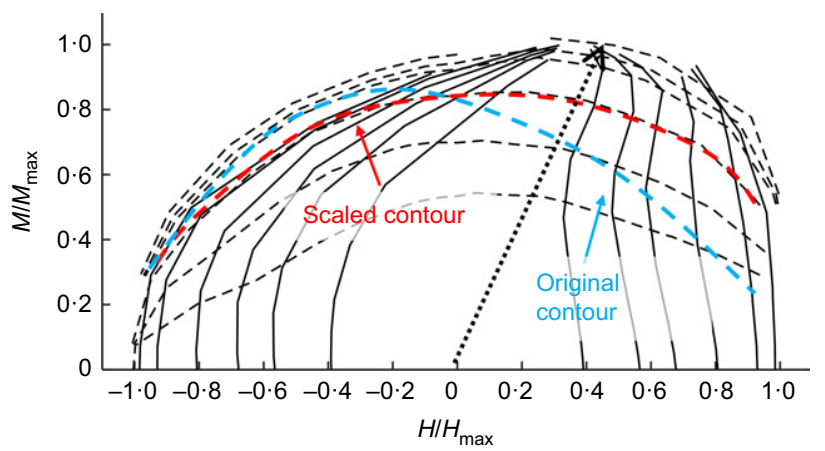

(a)

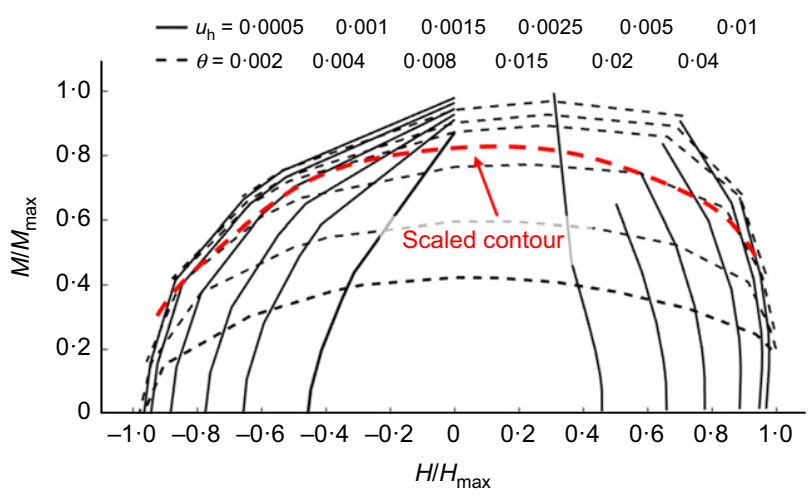

(b)

Fig. 21. Demonstration of the procedure for scaling response diagrams based on geometry: (a) scaled diagram $(h / D=1 \cdot 0$ to $h / D=0 \cdot 25)$; (b) computed diagram by 3D FEA for $h / D=0 \cdot 25$

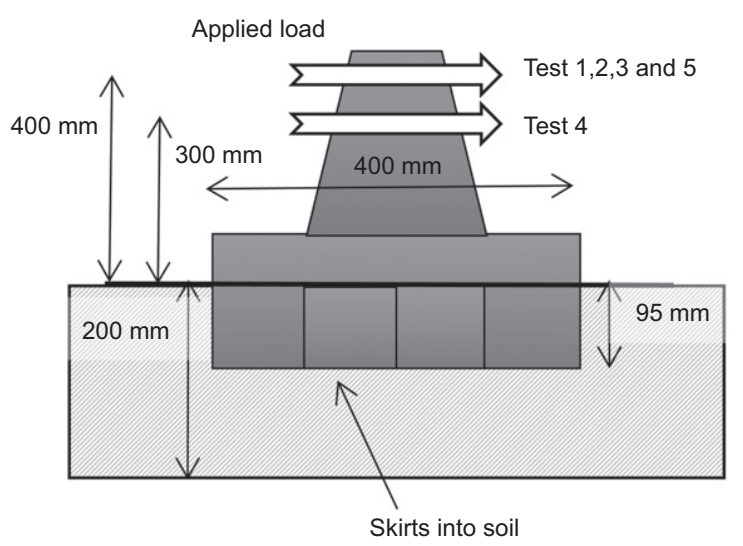

Fig. 22. Illustration of the test model geometry

stress was around $13 \mathrm{kPa}$ at $50 \mathrm{~mm}$ depth giving an $\mathrm{OCR}=3 \cdot 4$, and $s_{\mathrm{u}}^{\mathrm{DSS}}=6 \cdot 2 \mathrm{kPa}$ at the clay surface and $8 \mathrm{kPa}$ at skirt tip level. The foundation was subjected to cyclic loading at $1 \boldsymbol{g}$ condition. More details about the test can be found in the referred papers. The back-calculated test denoted test 2 in the original papers was run with perfect two-way cyclic horizontal loading and the vertical load equal to approximately $10-15 \%$ of the static vertical bearing capacity. The vertical load was neglected in the backcalculation for simplicity.

One estimate of the load-displacement response was based solely on the Drammen clay response diagrams in Fig. 16 and the scaling diagrams in Fig. 20. This represents a rough estimate where only the static vertical, horizontal and moment capacity were required input and the remaining information was taken from the diagrams in the paper (cyclic degradation, foundation aspect ratio and load path). In addition, a more refined estimate was carried out based on cyclic degradation

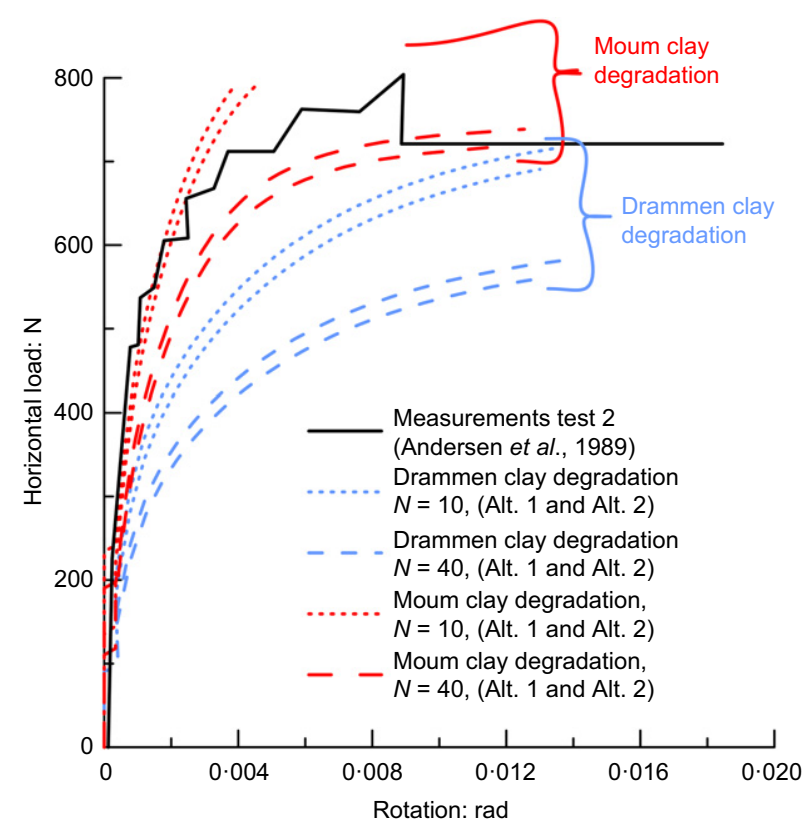

Fig. 23. Comparison between measurements (model test 2) and calculation based on degradation representing Drammen clay $\mathrm{OCR}=4$ and degradation representing Moum clay

for the Moum clay, and by scaling of displacements by the factors established from the uniaxial responses. Both estimates are explained by the following steps.

(a) The diagram in Fig. 16(a) represents $\mathrm{OCR}=4$, $F_{\mathrm{cy}} /\left(F_{\mathrm{cy}}+F_{\mathrm{a}}\right)=1$ and increasing shear strength profile. The model test strength profile has an increasing shear strength with depth. However, it also has a significant shear strength at the clay surface, making it different from the increasing shear strength profiles considered in Fig. 16. A reasonable approach is to consider the model test soil profile to be in-between a constant strength profile and a linear increasing profile. Thus, the diagram was scaled by equation (3) considering both alternatives: Alt. 1 - scaled by the addends relevant for an increasing shear strength profile (addends from Figs 20(a) and 20(c); the scaled diagram is shown in Fig. 21(a)); Alt. 2 - scaled by the addends relevant for a constant shear strength profile (addends from Figs 20(b) and 20(d)).

(b) The loads applied to the test model were transferred to the reference point at $2 h / 3$ (Alt. 1) and $h / 2$ (Alt. 2) depth. This gave a ratio of horizontal load over moment load: $H / M=2 \cdot 158$ for reference point $2 h / 3$ and $H / M=2 \cdot 24$ for reference point $h / 2$.

(c) To determine the load path in the response diagram, the load ratio has to be normalised by the ratio between the corresponding uniaxial failure loads. The static or average failure loads for the model test were calculated by HVMCap FEA: $H_{\mathrm{a}, \mathrm{ref}}=2244 \mathrm{~N}$ and $M_{\mathrm{a}, \text { ref }}=420 \mathrm{Nm}$. For the model test conditions, with low $h / D$ ratio, the average failure loads were similar for both load reference points. The capacities gave a ratio between the static horizontal and moment failure loads equal $H_{\mathrm{a} \text {,ref }} / M_{\mathrm{a} \text {,ref }}=5 \cdot 343$. The load path to be applied in the relevant response diagram was then calculated as

$$
\begin{aligned}
& \frac{H / H_{\max }}{M / M_{\max }}=\frac{H / M}{H_{\mathrm{a}, \text { ref }} / M_{\mathrm{a}, \text { ref }}}=\frac{2 \cdot 158}{5 \cdot 343}=0.404 \\
& \frac{H / H_{\mathrm{a}, \text { ref }}}{M / M_{\mathrm{a}, \text { ref }}}=\frac{H / M}{H_{\mathrm{a}, \text { ref }} / M_{\mathrm{a}, \text { ref }}}=\frac{2 \cdot 24}{5 \cdot 343}=0.420
\end{aligned}
$$


for the reference point at $2 h / 3$ depth (Alt. 1) and $h / 2$ depth (Alt. 2), respectively.

(d) The ratios found in equation (4) were then applied as load paths in the updated response diagram. For illustration, the path representative for the reference point $2 h / 3$ (Alt. 1 ) is indicated by the arrow in Fig. 21(a). Based on the contour lines being crossed by this load path, a normalised load-displacement curve was extracted.

(e) At this stage, the normalised curve could have been scaled by equation (1). For the rough estimate, no such scaling was performed and the normalised load-displacement response was used directly. In the refined estimate, the rotation was scaled by equation (1) based on the parameters in Table 2 .

( $f$ ) The loads in the normalised curves were then de-normalised by the static failure loads $\left(F_{\mathrm{a}, \text { ref }}\right)$ and the ratio between cyclic capacity $\left(F_{\text {cy }}+F_{\mathrm{a}}\right)$ and $F_{\text {a,ref, }}$ according to $N_{\text {eq }}$ for the curve representing $F_{\text {cy }} /\left(F_{\text {cy }}+F_{\text {a }}\right)=1$ in Fig. 9(a). The strain accumulation procedure for the model test shows that $N_{\text {eq }}$ varies through the loading history between $N_{\text {eq }}=10$ and $N=38$ (Andersen et al., 1989). This means that the two values represent an upper and lower bound of the response throughout the history. The values of 0.85 and 0.69 was found to represent $N_{\text {eq }}$ of 10 and 40 according to the curves representing Drammen clay OCR $=1$ and 4 in Fig. 9(a). The cyclic degradation of Moum clay has not been as extensively studied as the Drammen clay. However, cyclic degradation ratios $\left(\left(F_{\mathrm{cy}}+F_{\mathrm{a}}\right) / F_{\mathrm{a} \text {,ref }}\right)$ were established specifically for $N_{\text {eq }}=10$ and 40 based on HVMCap results. The Moum clay was found to have cyclic degradation ratios of 1.03 for $N_{\mathrm{eq}}=10$ and 0.84 for $N_{\text {eq }}=40$, which are approximately $20 \%$ higher than for Drammen clay.

( $g$ ) The horizontal displacements were finally de-normalised according to the foundation geometry (diameter, $D$, and skirt depth, $h$ ).

Through the described steps, eight sets of load-displacement curves have been established representing $N_{\text {eq }}=10$ or 40 , scaling based on increasing strength profile (Alt. 1) or constant strength profile (Alt. 2) and cyclic degradation based on Drammen clay $\mathrm{OCR}=4, F_{\text {cy }} /\left(F_{\text {cy }}+F_{\mathrm{a}}\right)=1$ and Moum clay $\mathrm{OCR}=3 \cdot 4, F_{\text {cy }} /\left(F_{\text {cy }}+F_{\mathrm{a}}\right)=1$. Fig. 23 shows the computed and measured cyclic amplitude of the rotations as a function of the horizontal load. The comparison reveals that the calculation procedures based on Drammen clay under-predict the stiffness and capacity. This is the case for both Alt. 1 and Alt. 2. The load-displacement response based on Moum clay shows a relatively good agreement with the measurements. The agreement shows that the procedures are capable of predicting the model test response relatively accurately. There are two likely reasons for the disagreement between the estimate based on Drammen clay and the model test measurements. First, the strength of Drammen clay OCR $=1$ and 4 reduces more rapidly than Moum clay when subjected to cyclic loading. Second, the calculation procedure reduces the stiffness due to cyclic loading at low mobilisation levels equal to the stiffness reduction close to failure. This is a simplification, as the cyclic degradation increases with mobilisation and the initial stiffness is unaffected by $N_{\text {eq }}$ (Andersen et al., 1980). The disagreement may also reflect inaccuracy in the measurements as discussed in Jostad \& Andresen (2009). The comparison also shows that the moment-rotation response calculated by Alt. 1 and Alt. 2 is almost similar for the foundation geometry considered. The comparison with Moum clay, which is more resistant to cyclic degradation than the Drammen clay
OCR $=1$ and 4 , illustrates the importance of including results from cyclic tests on the actual soil. The relevance of the data presented herein should therefore be evaluated by comparing the degradation behaviour specifically.

\section{CONCLUSIONS}

The response of skirted foundations subjected to combined static and cyclic general loading has been studied based on FEA and the cyclic behaviour of Drammen clay as described by the NGI procedure for cyclic loading. The study has focused on failure envelopes, their sensitivity to cyclic degradation, foundation geometry and shear strength profiles, and finally cyclic displacement response and scaling procedures for usage of response diagrams to estimate stiffness. The investigation has led to a framework that can be used to estimate foundation response. The results can also serve as the basis for developments of macro elements.

The computed uniaxial foundation capacities for the different combinations of cyclic-to-total load ratio and number of equivalent cycles for Drammen clay with $\mathrm{OCR}=1,4$ and 40 have been used to define trend lines which quantify the reduction in foundation capacity due to cyclic loading. The reduction is expressed as the cyclic capacity normalised by the static reference capacity $\left(F_{\text {cy }}+F_{\mathrm{a}}\right) / F_{\mathrm{a} \text {,ref. }}$ The differences in the cyclic degradation for vertical, horizontal and moment loading were negligible, thus the same reduction ratio can be applied to all load components. It was also demonstrated that the normalised reductions in capacity were very similar for Drammen clay with $\mathrm{OCR}=1$ and 4 . Degradation trend lines valid for $\mathrm{OCR}=1$ and 4 were therefore suggested. Separate degradation trend lines were given for OCR $=40$. The diagrams are efficient for estimating the effect of cyclic degradation on the foundation level when the $N_{\text {eq }}$ has been determined by NGI's cyclic accumulation procedure.

It was found that changes in cyclic-to-total load ratio and number of equivalent cycles, for a given foundation aspect ratio, had limited effect on the shape of the failure envelopes. A distinct difference in the shape of the failure envelope was found by comparing profiles with constant and increasing shear strength with depth. The observed agreement between the failure surfaces makes it possible to scale the failure envelope from a static reference failure envelope to the relevant cyclic degradation (expressed by $N_{\text {eq }}$ and cyclic-to-total load ratio) without changing the shape of the failure envelope.

The paper further demonstrates how contours of displacements can be included in the diagrams. These contours give more complete information of the foundation response. The displacement contours clearly show that the interactions between the load components change, depending on the global mobilisation. For demonstration, a database of foundation response has been established for a reference case with aspect ratio $h / D=1$ and cyclic degradation $N_{\text {eq }}=10$. The reference case database contains the normalised response for different OCRs and cyclic-to-total load ratios $(\mathrm{OCR}=1,4$ and 40 , cyclic-to-total load ratio $F_{\text {cy }} /\left(F_{\text {cy }}+F_{\text {cy }}\right)=1,2 / 3,1 / 2$ and 1$)$. The database was accompanied by a procedure to make the database applicable for a wider range of foundation geometries (size and aspect ratio of the foundation), a procedure to account for differences in the load-displacement response due to different stress-strain relationships and a procedure to account for cyclic degradation.

The application of the procedure was demonstrated by back-calculating the load-displacement response of a $1 \boldsymbol{g}$ model test. The back-calculation showed that the procedure 
works as intended, but that the results may be improved with site-specific cyclic data.

The displacement diagram and the procedures presented in the paper provide a framework for estimating the response of skirted foundations for general cyclic loading. The framework offers different levels of sophistication, from computation of response in the full 3D load space by a set of FEA including exact conditions for the considered problem, to simplified procedures utilising a base response diagram and the scaling procedures to account for the different effects.

\section{ACKNOWLEDGEMENTS}

The authors would like to acknowledge the valuable comments from Amir M. Kaynia, Youhu Zhang, Hendrik Sturm and the discussions with Knut H. Andersen. The financial support by the Norwegian Research Council and the industrial partners Statoil, Vattenfall and Statkraft through the project 'Reducing cost of offshore wind by integrated structural and geotechnical design (REDWIN)', grant no. 243984, is gratefully acknowledged.

\section{NOTATION}

$D$ foundation diameter

F load vector consisting of $V, H, M$

$F_{\text {a }}$ average load

$\boldsymbol{F}_{\text {a,ref }} \quad$ static reference capacity vector $\left[V_{\text {a,ref }}, H_{\text {a,ref }}, M_{\text {a,ref }}\right]$

$F_{\text {cy }} \quad$ cyclic load amplitude

$g_{\mathrm{h}, \mathrm{const}}$ addends for horizontal displacement contours for profiles with constant shear strength

$g_{\mathrm{h} \text {,inc }}$ addends for horizontal displacement contours for profiles with increasing shear strength with depth

$g_{\theta, \text { const }}$ addends for rotational displacement contours for profiles with constant shear strength

$g_{\theta \text {,inc }}$ addends for rotational displacement contours for profiles with increasing shear strength with depth

$H$ horizontal load of the foundation's reference point

$H_{\text {max }}$ maximum horizontal load (uniaxial vertical capacity)

$h$ foundation skirt depth

$h^{\prime} \quad$ vertical load, $V$, normalised by $V_{\max }$

$h^{\prime}$ horizontal load, $H$, normalised by $H_{\max }$

$h_{\text {upd }}^{\prime}$ normalised horizontal load updated by the procedure accounting for aspect ratio

$M$ moment load of foundation's reference point

$M_{\max }$ maximum moment load (uniaxial vertical capacity)

$m^{\prime}$ moment load, $M$ normalised by $M_{\max }$

$m_{\text {upd }}^{\prime}$ normalised moment load updated by the procedure accounting for aspect ratio

$N$ number of cycles

$N_{\text {eq }} \quad$ equivalent number of cycles

$r_{\mathrm{ss}}, r_{\mathrm{sb}}$ three-dimensional side shear factors

$s_{\mathrm{u}, \mathrm{c}} \quad$ constant shear strength

$s_{\mathrm{u} 0} \quad$ undrained shear strength at seabed

$s_{\mathrm{u}}^{\mathrm{C}} \quad$ undrained direct simple shear strength

$s_{\mathrm{u}}^{\mathrm{DSS}}$ undrained direct simple shear strength

$u$ general displacement variable in $\zeta$ representing $u_{\mathrm{v}}, u_{\mathrm{h}}$ or $\theta$

$u_{\mathrm{a}}$ average pore pressure

$u_{\text {cy }} \quad$ cyclic pore pressure amplitude

$u_{\mathrm{f}}$ reference displacement in $\zeta$ representing $u_{\mathrm{v}, \mathrm{f}}, u_{\mathrm{h}, \mathrm{f}}$ or $\theta_{\mathrm{f}}$

$u_{\mathrm{h}}$ horizontal displacement of foundation's reference point

$u_{\mathrm{v}}$ vertical displacement of foundation's reference point

$V$ vertical load of foundation's reference point

$V_{\max }$ maximum vertical load (uniaxial vertical capacity)

$\alpha$ soil skirt interface reduction factor

$\beta_{1}, \beta_{2}, \lambda$ parameters in the scaling function, $\zeta$

$\gamma_{\mathrm{a}}$ average strain stress

$\gamma_{\text {cy }} \quad$ cyclic shear strain amplitude

$\zeta$ scaling function expressed generally for any of the three degrees of freedom

$\zeta_{\mathrm{h}} \quad$ scaling function for the horizontal displacement

$\zeta_{\mathrm{v}}$ scaling function for the vertical displacement

$\zeta_{\theta}$ scaling function for the rotation $\theta$ foundation rotation

$\sigma_{\mathrm{pc}}^{\prime} \quad$ vertical preconsolidation pressure

$\sigma_{\mathrm{v}}^{\prime} \quad$ vertical effective stress

$\tau_{\mathrm{a}}$ average shear stress

$\tau_{\text {cy }} \quad$ cyclic shear stress amplitude

\section{REFERENCES}

Andersen, K. H. (1976). Behaviour of clay subjected to undrained cyclic loading. Proceedings of the international conference on the behaviour of offshore structures, Trondheim, Norway, vol. 1 , pp. 392-403.

Andersen, K. H. (2004). Cyclic clay data for foundation design of structures subjected to wave loading. In Cyclic behaviour of soils and liquefaction phenomena (ed. Th. Triantafyllidis), pp. 371-387. Rotterdam, the Netherlands: AA Balkema.

Andersen, K. H. (2015). Cyclic soil parameters for offshore foundation design. In Frontiers in offshore geotechnics III (ed. V. Meyer), ch. 2, pp. 5-82. Leiden, the Netherlands: CRC Press/Balkema.

Andersen, K. H. \& Jostad, H. P. (1999). Foundation design of skirted foundations and anchors in clay. Proceedings of the offshore technology conference, Houston, TX, USA, vol. 1, pp. 383-392, paper OTC 10824.

Andersen, K. H. \& Jostad, H. (2002). Shear strength along outside wall of suction anchors in clay after installation. In Proceedings of the 12th international offshore and polar engineering conference (eds J. S. Chung, T. Matsui, J.-W. Chen and Y. Kyozuka), vol. 2, pp. 785-794. Cupertino, CA, USA: International Society of Offshore and Polar Engineers.

Andersen, K. H., Rosenbrand, W. F., Brown, S. F. \& Pool, J. H. (1980). Cyclic and static laboratory tests on Drammen clay. J. Geotech. Engng Div. 106, No. 5, 499-529.

Andersen, K. H., Dyvik, R., Lauritzsen, R., Heien, D., Harvik, L. \& Amundsen, T. (1989). Model tests of gravity platforms. II: interpretation. J. Geotech. Engng 115, No. 11, 1550-1568.

Andersen, K. H., Dyvik, R., Schroder, K., Hansteen, O. E. \& Bysveen, S. (1993). Field tests of anchors in clay II: predictions and Interpretation. J. Geotech. Engng 119, No. 10, 1532-1549.

Andersen, K. H., Murff, J. D., Randolph, M. F., Clukey, E. C., Erbrich, C. T., Jostad, H. P., Hansen, B., Aubeny, C., Sharma, P. \& Supachawarote, C. (2005). Suction anchors for deepwater applications. Keynote paper. In Frontiers in offshore geotechnics (eds S. Gourvenec and M. Cassidy), pp. 3-30. Boca Raton, FL, USA: CRC Press.

Andersen, K., Puech, A. A. \& Jardine, R. J. (2013). Cyclic resistant geotechnical design and parameter selection for offshore engineering and other applications. In Proceedings of TC 209 workshop - design for cyclic loading: piles and other foundations (ed. A. Puech), pp. 9-44. Paris, France: Presses des Ponts.

Bjerrum, L. (1967). Engineering geology of Norwegian normallyconsolidated marine clays as related to settlements of buildings. Géotechnique 17, No. 2, 83-118, http://dx.doi.org/10.1680/geot. 1967.17.2.83.

Bjerrum, L. \& Landva, A. (1966). Direct simple-shear tests on a Norwegian quick clay. Géotechnique 16, No. 1, 1-20, http://dx.doi.org/10.1680/geot.1966.16.1.1.

Bjerrum, L., Simons, N. \& Torblaa, I. (1958). The effect of time on the shear strength of a soft marine clay. Proceedings of the Brussels conference on earth pressure problems, vol. I, pp. 148-158.

Bransby, M. F. \& Yun, G. J. (2009). The undrained capacity of skirted strip foundations under combined loading. Géotechnique 59, No. 2, 115-125, http://dx.doi.org/10.1680/geot.2007.00098.

Brinch Hansen, J. (1961). A general formula for bearing capacity, Bulletin 11. Copenhagen, Denmark: The Danish Geotechnical Institute.

Brinch Hansen, J. (1970). A revised and extended formula for bearing capacity, Bulletin 28, pp. 5-11. Copenhagen, Denmark: The Danish Geotechnical Institute.

Cassidy, M. J., Byrne, B. W. \& Randolph, M. F. (2004). A comparison of the combined load behaviour of spudcan and caisson foundations on soft normally consolidated clay. Géotechnique 54, No. 2, 91-106, http://dx.doi.org/10.1680/geot. 2004.54.2.91

Chen, W. \& Randolph, M. F. (2007). External radial stress changes and axial capacity for suction caissons in soft clay. Géotechnique 
57, No. 6, 499-511, http://dx.doi.org/10.1680/geot.2007.57.6. 499.

Clausen, C. J. F., Dibiagio, E. J. F., Duncan, J. M. \& Andersen, K. H. (1975). Observed behavior of the Ekofisk oil storage tank foundation. Proceedings of the offshore technology conference, Houston, TX, USA, vol. 3, pp. 399-413, paper OTC 2373.

Dyvik, R., Andersen, K. H., Madshus, C. \& Amundsen, T. (1989). Model tests of gravity platforms. I: description. J. Geotech. Engng 115, No. 11, 1532-1549.

El Sawwaf, M. \& Nazer, A. (2005). Behavior of circular footings resting on confined granular soil. J. Geotech. Geoenviron. Engng 131, No. 3, 359-366.

Fan, Q. L., Luan, M. T. \& Gong, X. B. (2012). A unified equation of failure envelope for skirted foundations in normally consolidated clay. Chin. J. Geotech. Engng 34, No. 10, 1917-1924.

Gerolymos, N., Zafeirakos, A. \& Karapiperis, K. (2015). Generalized failure envelope for caisson foundations in cohesive soil: static and dynamic loading. Soil Dynamics Earthquake Engng 78, 154-174, https://doi.org/10.1016/ j.soildyn.2015.07.012.

Gottardi, G. \& Butterfield, R. (1993). On the bearing capacity of surface footings on sand under general planar loads. Soils Found. 33, No. 3, 68-79.

Gourvenec, S. (2008). Effect of embedment on the undrained capacity of shallow foundations under general loading. Géotechnique 58, No. 3, 177-185, http://dx.doi.org/10.1680/ geot.2008.58.3.177.

Gourvenec, S. \& Barnett, S. (2011). Undrained failure envelope for skirted foundations under general loading. Géotechnique 61, No. 3, 263-270, http://dx.doi.org/10.1680/geot.9.T.027.

Gourvenec, S. \& Randolph, M. (2003). Effect of strength nonhomogeneity on the shape of failure envelopes for combined loading of strip and circular foundations on clay. Géotechnique 53, No. 6, 575-586, http://dx.doi.org/10.1680/geot.2003. 53.6.575.

Grimstad, G., Andresen, L. \& Jostad, H. P. (2012). NGI-ADP: anisotropic shear strength model for clay. Int. J. Numer. Analyt. Methods Geomech. 36, No. 4, 483-497.

Houlsby, G. T. \& Cassidy, M. J. (2002). A plasticity model for the behaviour of footings on sand under combined loading. Géotechnique 52, No. 2, 117-129, http://dx.doi.org/10.1680/ geot.2002.52.2.117.

Ibsen, L., Barari, A. \& Larsen, K. (2014). Adaptive plasticity model for bucket foundations. J. Engng Mech. 140, No. 2, 361-373.

Ishihara, K., Tatasuoka, F. \& Yasuada, S. (1975). Undrained deformation and liquefaction of sand under cyclic stresses. Soils Found. 15, No. 1, 29-44.

Jostad, H. P. \& Andersen, K. H. (2006). Potential benefits of using skirted foundations for jackup platforms. Proceedings of the offshore technology conference, Houston, TX, USA, paper OTC 18016.

Jostad, H. P. \& Andresen, L. (2009). A FE procedure for calculation of displacements and capacity of foundations subjected to cyclic loading. Proceedings of the 1st international symposium on computational geomechanics (ComGeo I), Juan-les-Pins, France, pp. 719-730.

Jostad, H. P. \& Andersen, K. H. (2015). Calculation of undrained holding capacity of suction anchors in clays. In Frontiers in offshore geotechnics III (ed. V. Meyer), pp. 263-268. Leiden, the Netherlands: CRC Press/Balkema.

Jostad, H. P., Nadim, F. \& Andersen, K. H. (1994). A computational model for fixity of spud cans on stiff clay. Proceedings of the 7th international conference on the behaviour of offshore structures: geotechnics, Boston, MA, USA, vol. 1, pp. 151-172.

Jostad, H. P., Grimstad, G. Andersen, K. H., Saue, M., Shin, Y. \& You, D. (2014). A FE procedure for foundation design of offshore structures - applied to study a potential OWT monopile foundation in the Korean Western Sea. Geotech. Engng 45, No. 4, 63-72.

Mana, D. S. K., Gourvenec, S. \& Randolph, M. F. (2013). Experimental investigation of reverse end bearing of offshore shallow foundations. Can. Geotech. J. 50, No. 10, 1022-1033.
Martin, C. M. (1994). Physical and numerical modelling of offshore foundations under combined loads. $\mathrm{PhD}$ thesis, University of Oxford, Oxford, UK.

Mathworks (2017). Matlab. Natick, MA, USA: Mathworks. See https://se.mathworks.com/products/matlab.html (accessed 13/07/2017).

Meyerhof, G. G. (1951). The ultimate bearing capacity of foundations. Géotechnique 2, No. 4, 301-332, http://dx.doi.org/ 10.1680/geot.1951.2.4.301.

Meyerhof, G. G. (1953). The bearing capacity of foundations under eccentric and inclined loads. Proceedings of the 3rd international conference on soil mechanics and foundation engineering, Zurich, Switzerland, vol. 1, pp. 440-445.

Norén-Cosgriff, K., Jostad, H. \& Madshus, C. (2015). Idealized load composition for determination of cyclic undrained degradation of soils. In Frontiers in offshore geotechnics III (ed. V. Meyer), pp. 1097-1102. Leiden, the Netherlands: CRC Press/Balkema.

Ntritsos, N., Anastasopoulos, I. \& Gazetas, G. (2015). Static and cyclic undrained response of square embedded foundations. Géotechnique 65, No. 10, 805-823, http://dx.doi.org/10.1680/ jgeot.14.P.205.

Plaxis (2015). http://www.plaxis.com (accessed 13/07/2017).

Randolph, M. \& Gourvenec, S. (2011). Offshore geotechnical engineering. Abingdon, UK: Spon Press.

Richardson, A. M. \& Whitman, R. V. (1963). Effect of strain-rate upon undrained shear resistance of a saturated remoulded fat clay. Géotechnique 13, No. 4, 310-324, http://dx.doi.org/ 10.1680/geot.1963.13.4.310.

Roscoe, K. H. \& Schofield, A. N. (1957). The stability of short pier foundations on sand, discussion. Br. Welding J., January, 12-18.

Seed, H. B. (1968). Landslides during earthquakes due to liquefaction. J. Soil Mech. Found. Div. ASCE 94, No. 5, 1055-1122.

Seed, H. B. \& Lee, K. L. (1966). Liquefaction of saturated sands during cyclic loading. J. Soil Mech. Found. Div. 92, No. 6, 105-134.

Singh, V. K., Prasad, A. \& Agrawal, R. K. (2007). Effect of soil confinement on ultimate bearing capacity of square footing under eccentric inclined load. Electronic J. Geotech. Engng 12, Bundle E, 1-14.

Skau, K. S. \& Jostad, H. P. (2014). Application of the NGIprocedure for design of bucket foundations for offshore wind turbines. Proceedings of the twenty-fourth international ocean and polar engineering conference, Busan, Korea, vol. 1, pp. 189-198.

Skjaeveland, H., Knudsen, A. \& Nyborg, A. (1994). Technical challenges in the design and construction of the troll gravity base structure. Proceedings of the 4th international offshore and polar engineering conference, Osaka, Japan, vol. IV, pp. 274-285.

Taiebat, H. A. \& Carter, J. P. (2000). Numerical studies of the bearing capacity of shallow foundations on cohesive soil subjected to combined loading. Géotechnique 50, No. 4, 409-418, http://dx.doi.org/10.1680/geot.2000.50.4.409.

Ukritchon, B., Whittle, A. J. \& Sloan, S. W. (1998). Undrained limit analyses for combined loading of strip footings on clay. J. Geotech. Geoenviron. Engng 124, No. 3, 265-276.

Villalobos, F. (2006). Model testing of foundations for offshore wind turbines. $\mathrm{PhD}$ thesis, University of Oxford, Oxford, UK.

Villalobos, F., Byrne, B. W., Houlsby, G. T. \& Martin, C. M. (2003). Bearing capacity tests of scale suction caisson footings on sand, experimental data. Data report FOT005/1. Oxford, UK: University of Oxford.

Vulpe, C. (2015). Design method for the undrained capacity of skirted circular foundations under combined loading: effect of deformable soil plug. Géotechnique 65, No. 8, 669-683, http://dx.doi.org/10.1680/geot.14.P.200.

Vulpe, C., Gourvenec, S. \& Power, M. (2014). A generalised failure envelope for undrained capacity of circular shallow foundations under general loading. Géotechnique Lett. 4, No. 3, 187-196, http://dx.doi.org/10.1680/geolett.14.00010.

Wichtmann, T., Niemunis, A. \& Triantafyllidis, T. (2009). Validation and calibration of a high-cycle accumulation model based on cyclic triaxial tests on eigth sands. Soils Found. 49, No. 5, 711-728. 